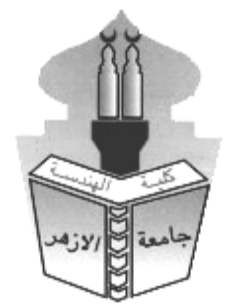

\title{
MPACT OF THE URBAN CHARACTERISTICS IN GATED COMMUNITIES ON FORMATION OF THE NEW CITIES SHEIKH ZAYED CITY AS A CASE STUDY
}

\author{
Ayman Hamza Thabet \\ Assistant Professor at the Institute of Architecture and Housing Research -National Center for \\ Housing and Construction Research- HBRC
}

\begin{abstract}
The paper focuses on analysis of the urban \& architect characteristics of the gated communities, and studying the impact of these characteristics on the homogeneity of urban features in new cities, in an attempt to monitor and analyze the pros and cons of this urban pattern, where the pattern of gated communities became the most prevalent pattern now in the new cities. Also studies how to exploit the characteristics of these communities to develop the new cities by achieving the homogeneity between these characteristics. With focusing on these axes as follows:-

* The urban fabric of these Gated communities in terms of: planning patterns, street networks, urban spaces design, motion paths, and services.

* Architectural features in terms of: elevations characteristics and styles, the means of security in terms of fences, gates and entrances. The paper ended by suggest some general controls to control the urban \& architect characteristics in the gated communities, to ensure the reduction the urban $\&$ architect heterogeneity problems that could be occur in these communities within the new cities in the future.

Keywords: Gated communities - Urban character - Urban fabric - Architectural character

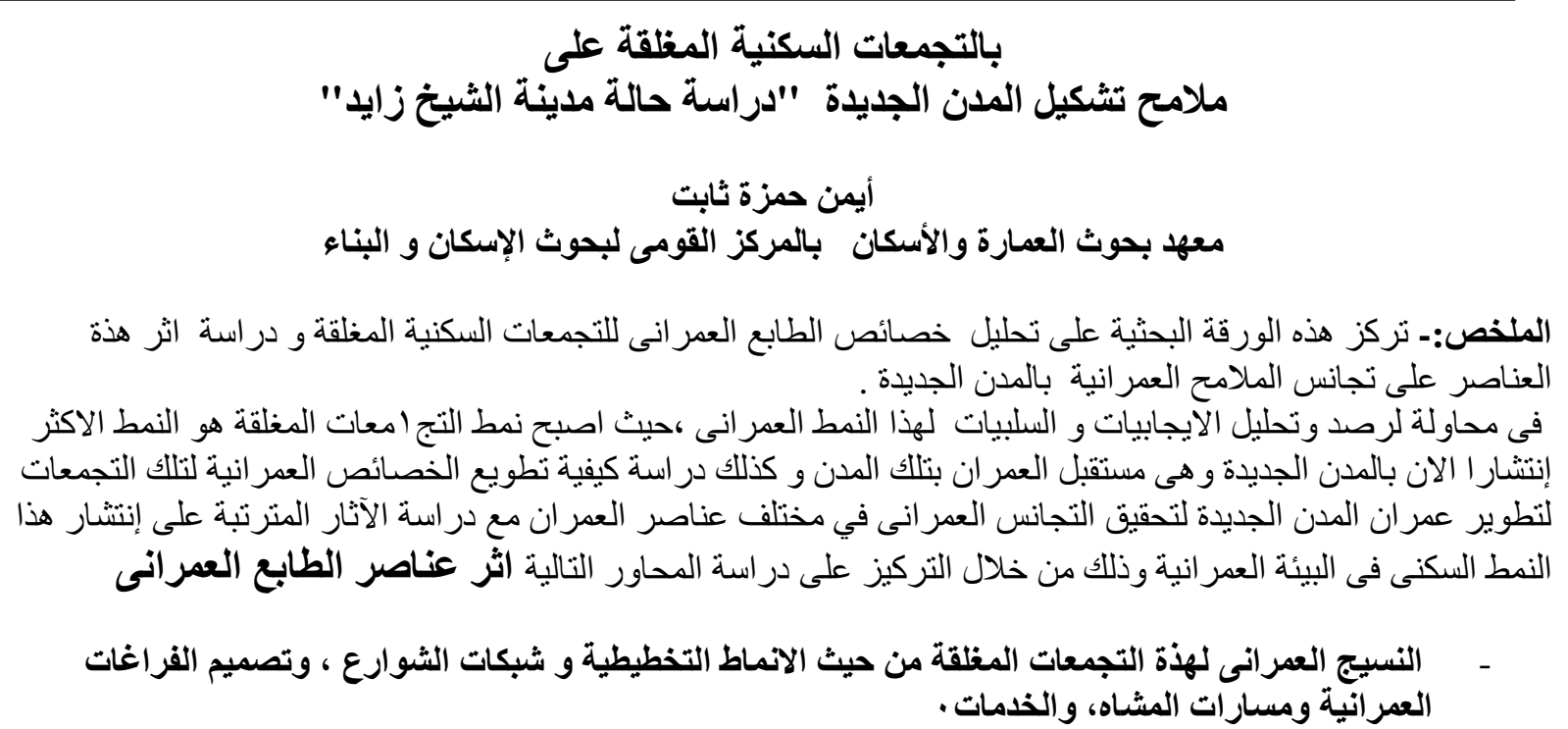




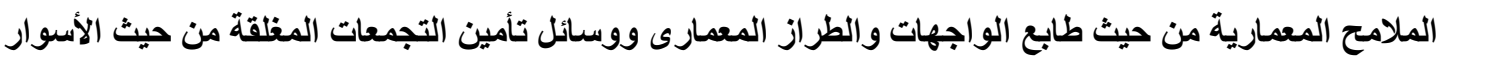

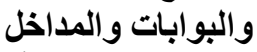

وتخلص الورقة البحثية إلى أن نمط التجمعات السكنية المغلقة هو نمط عمر انى منتشر بالمدن الجديدة ويمثل مستقبل العمر ان بها

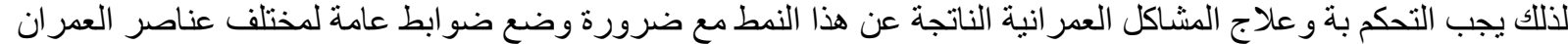

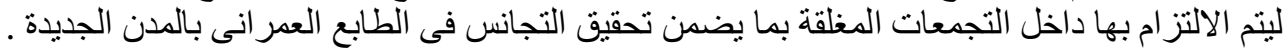

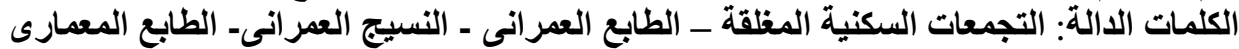

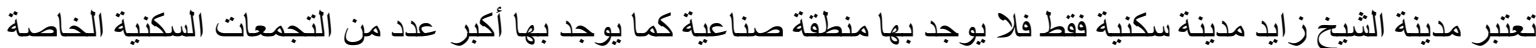

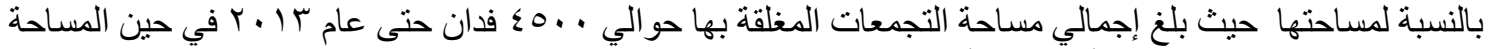

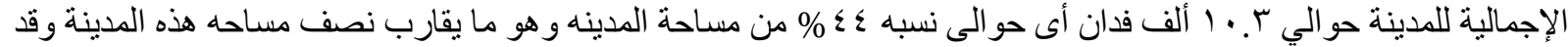

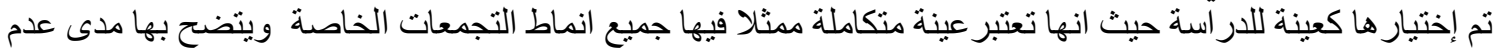

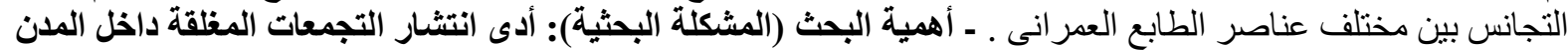

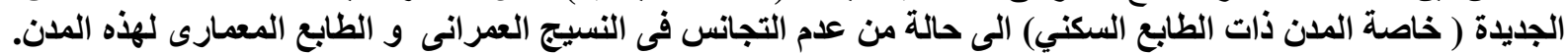

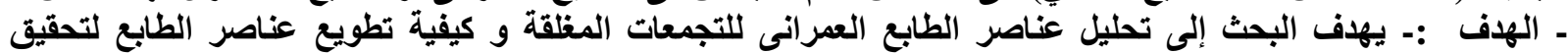

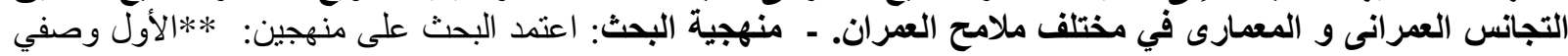

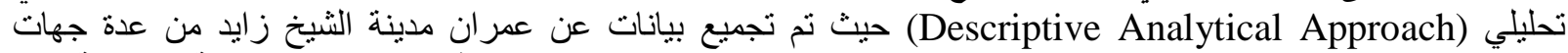

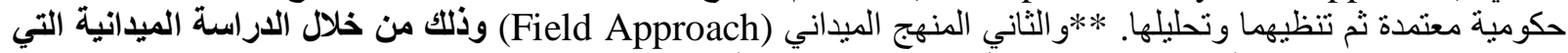

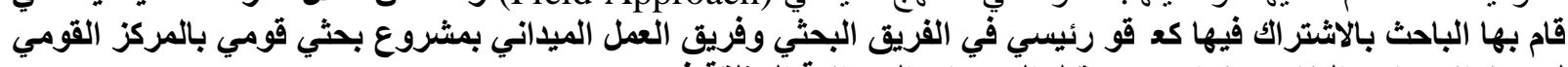

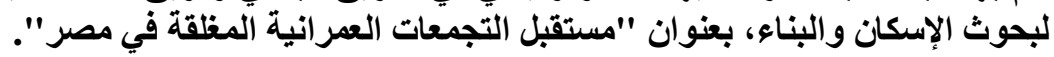

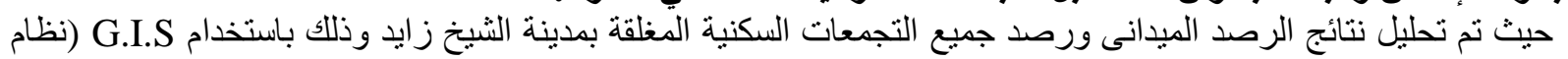

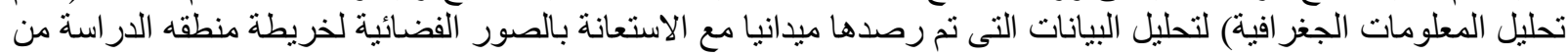

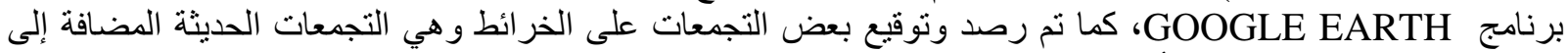

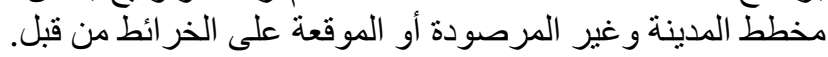

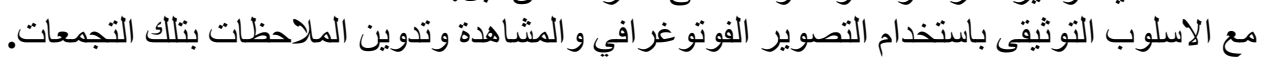

النظر التج من التجارب العالمية:-

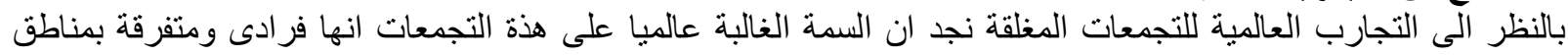

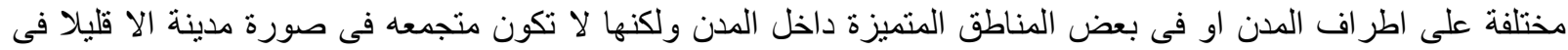

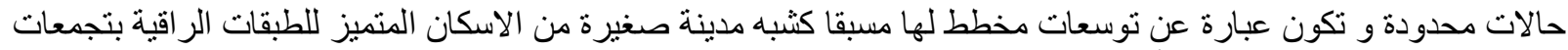

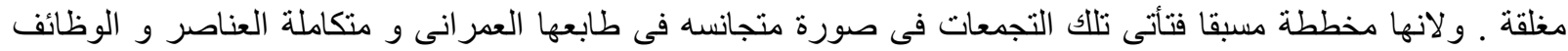

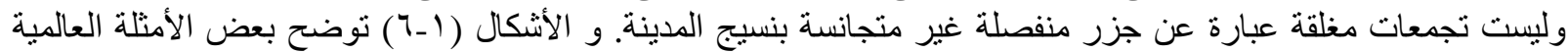

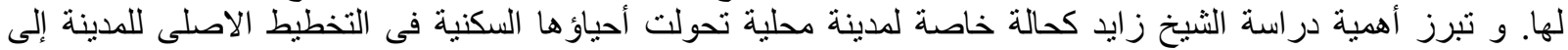

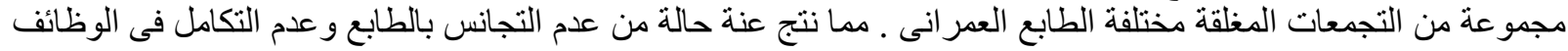

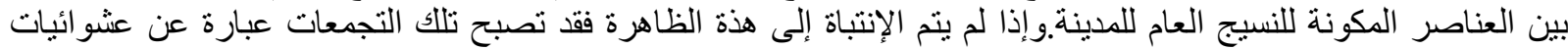

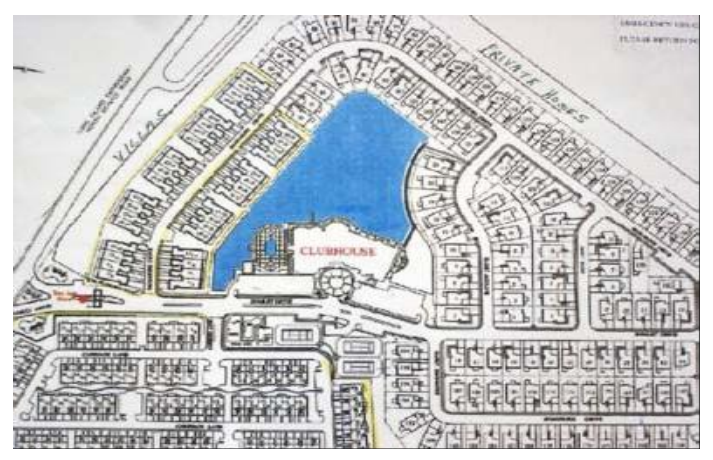

الطبقة المتميزة.

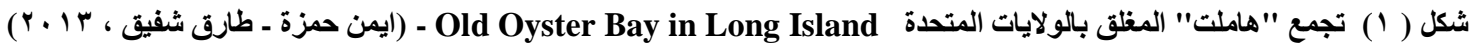



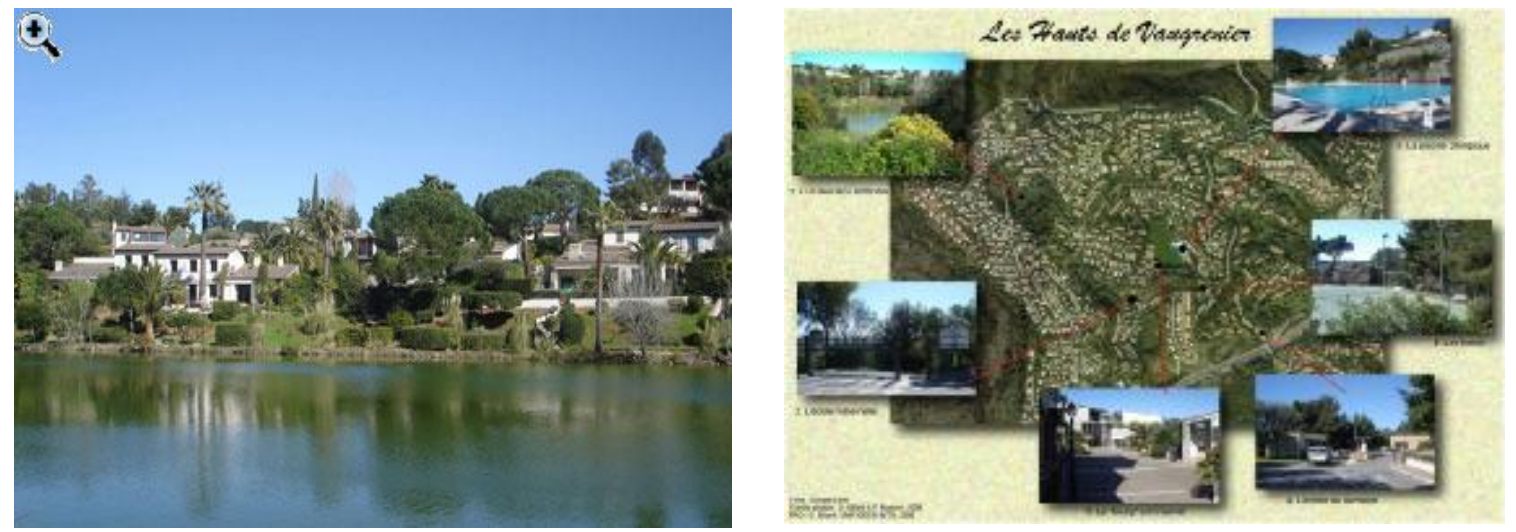

شكل (Y) التجمع المغلق Les Hauts de Vaugrenier بمدينة نيس - بفرنسا- شبة مدينة صغيرة مغلقة مخططة مسبقا

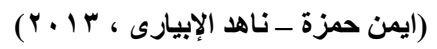
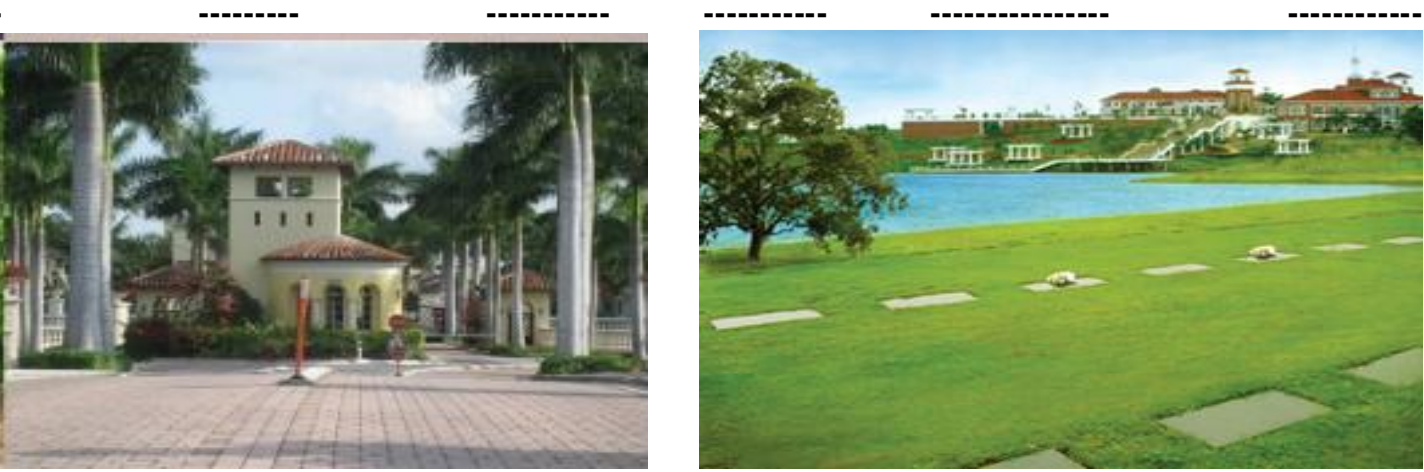

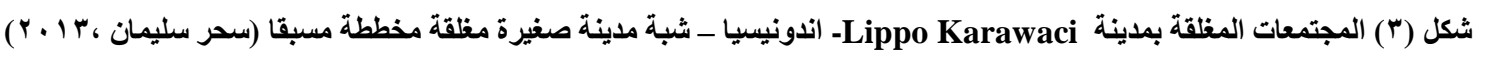
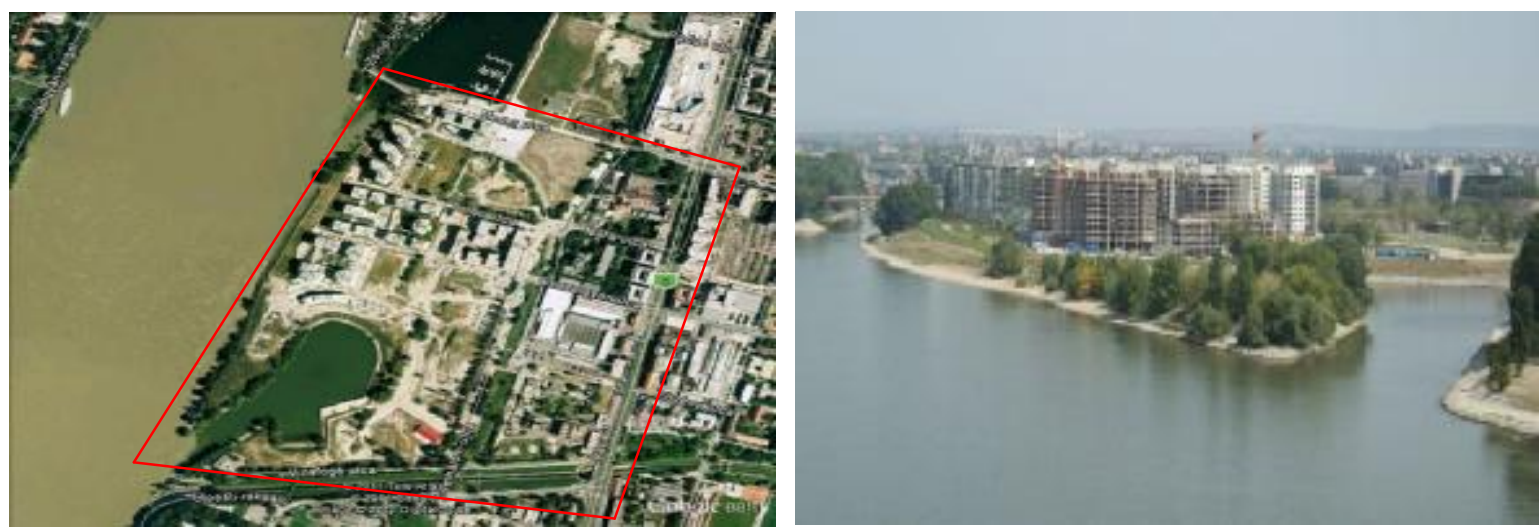

شكل (ع ) مشروع Marina Part السكنى- بودابست_المجر ( 


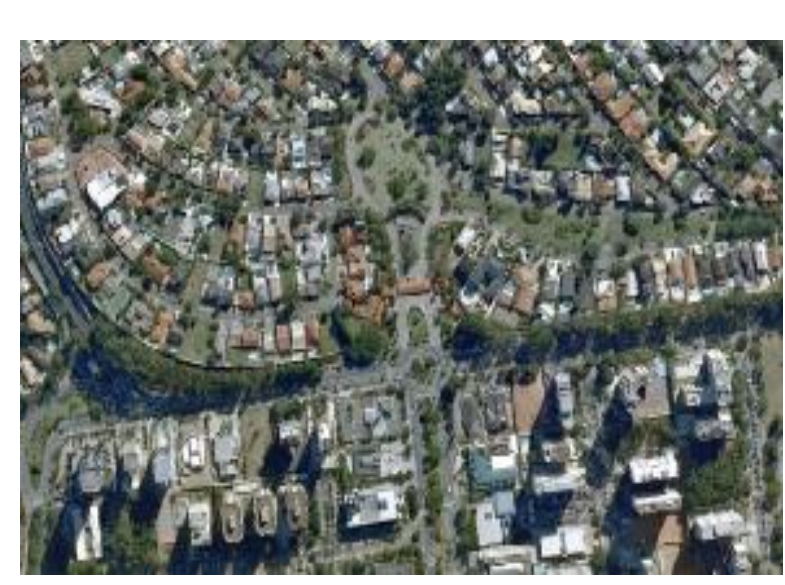

شكل (†) التجمع المغلق "Alphaville" بمدينة ساوياولو - البرازيل (https://www.thepolisblog.org -2018)

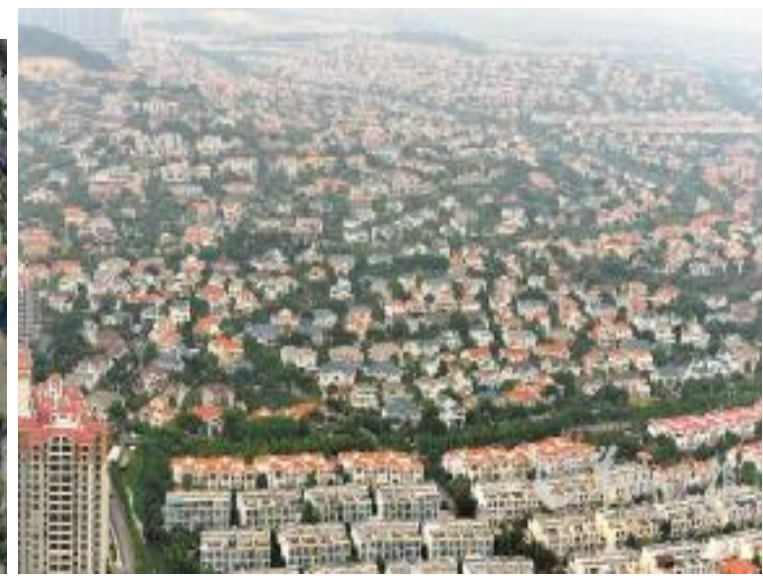

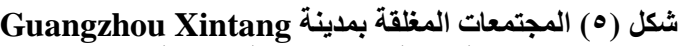
- بالصين - شبة مدينة صغيرة مغلقة مخططة مسبقا

(https://www.cliffordelementarybilingual.com-2018)

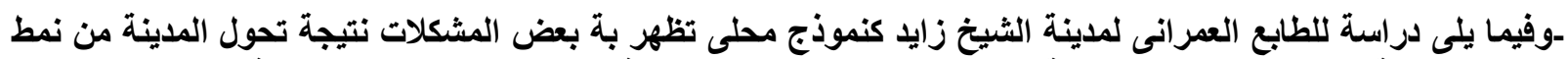

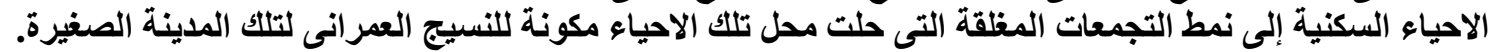

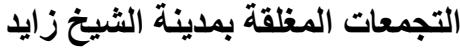

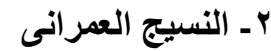
بـ ا ـ الانماط التخطيطية العمانية

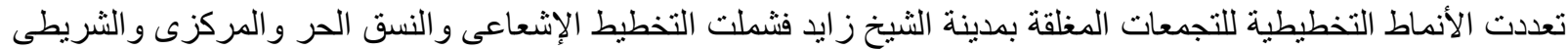

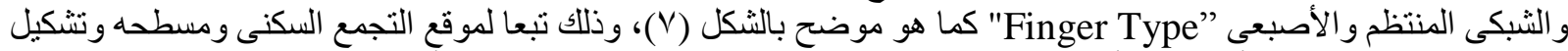

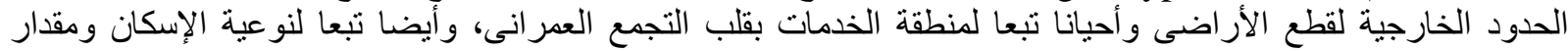
الخصوصية المر اد توفير ها بالمناطق السكية السكنية.

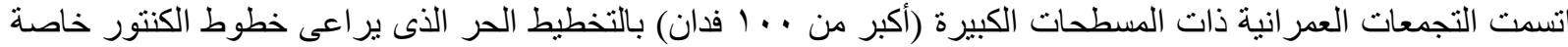

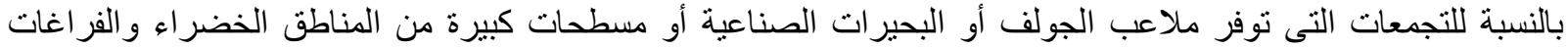

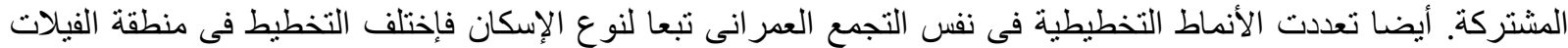

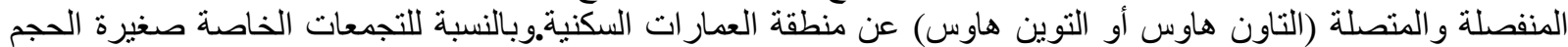
(التى يقل مسطحها عن • ( فدان) فإتسمت بالتخطيط الثريطى المتصن التصل أو المتقطع.

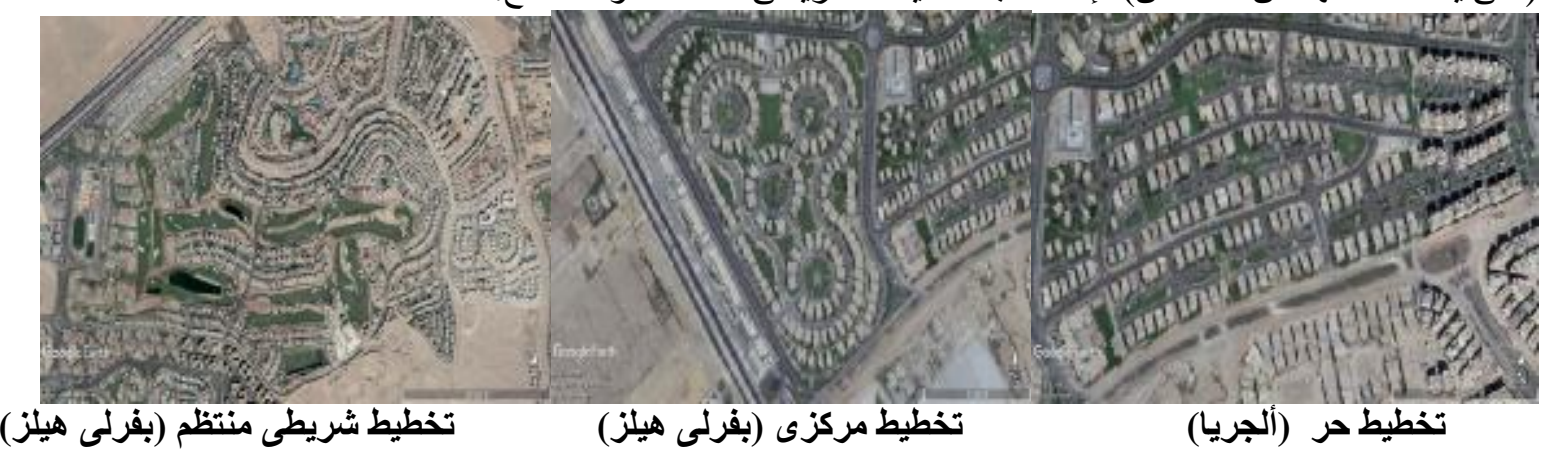


اثر عناصر الطابع العمر انى بالتجمعات السكنية المغلقة على ملامح تشكيل المدن الجديدة "دراسة حالة مدينة الثيخ زايد

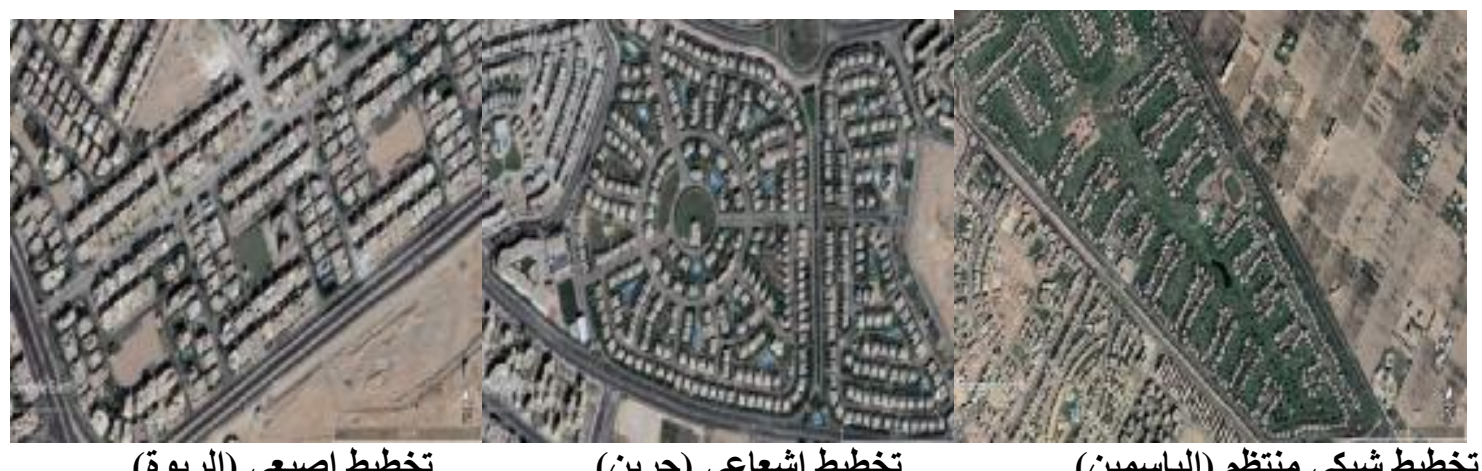

تخطيط اصبعى (الريوة)

تخطيط إثعاعى (جرين)

تخطيط شبكى منتظم (الياسمين)

شكل (V) الأنماط التخطيطية بالمجتمعات الخاصة

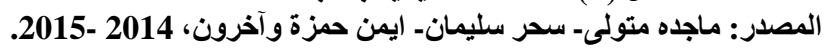

(www. google earth/historical imagery/(2017)

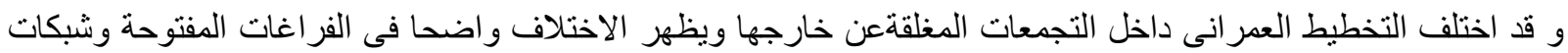

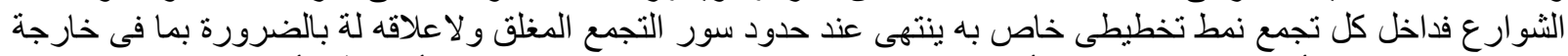

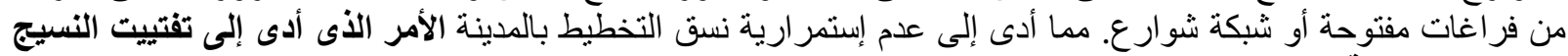

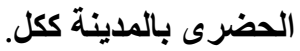

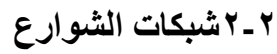

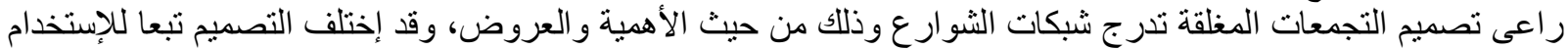

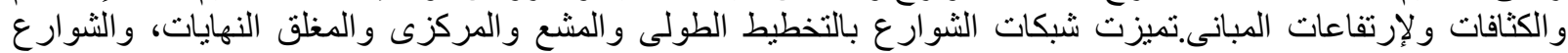

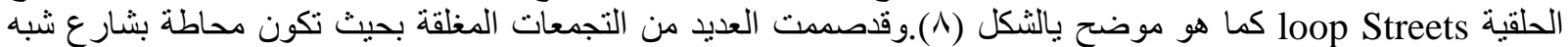

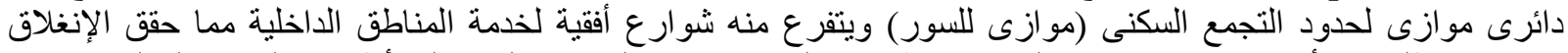

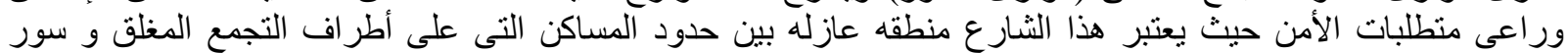

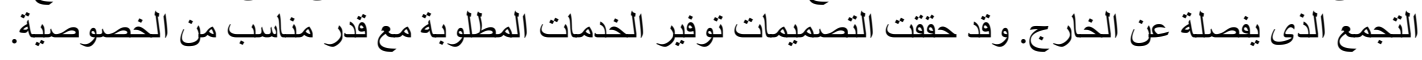

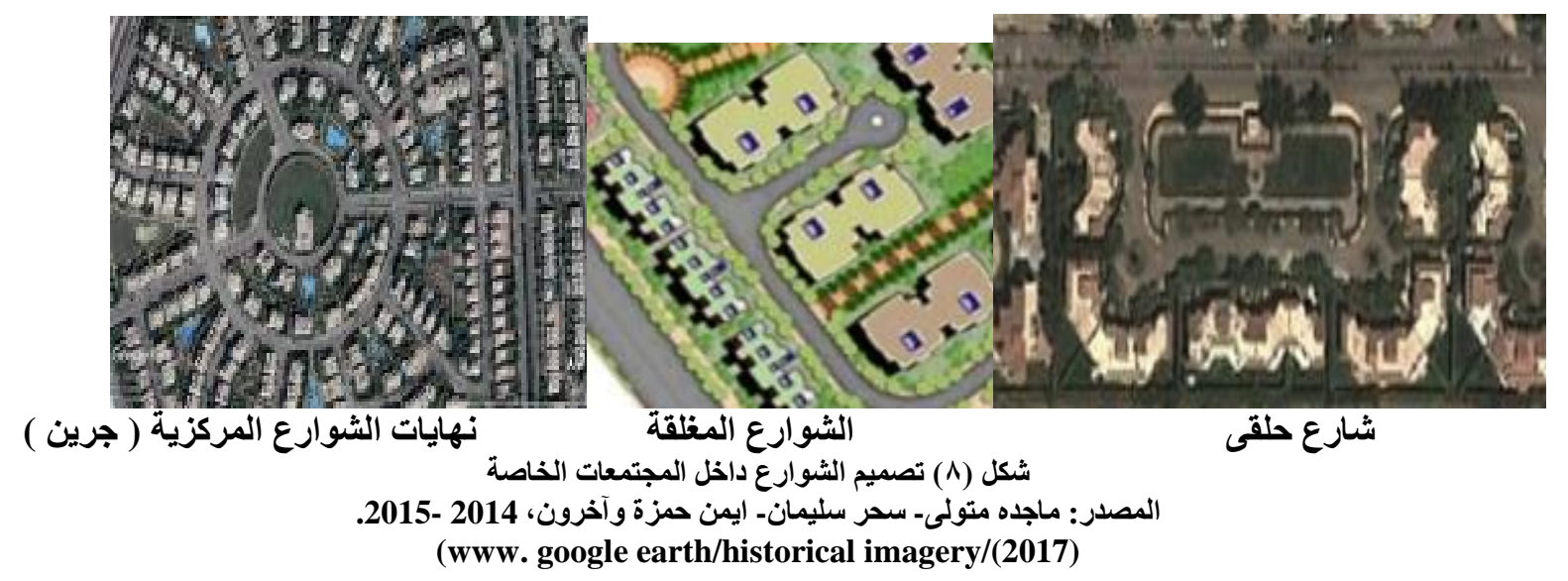

تقييم تصميم شبكات الشوارع 


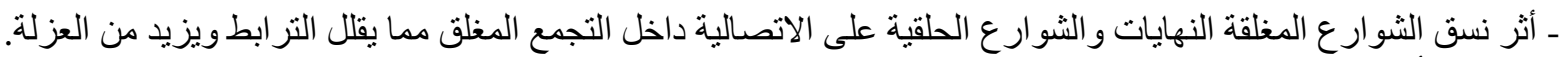

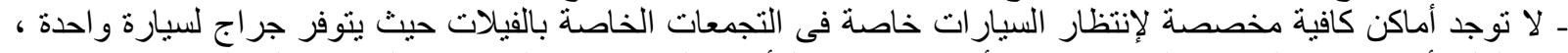

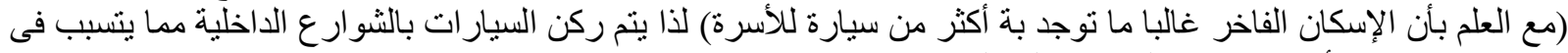

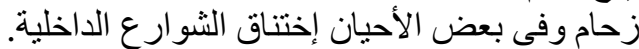

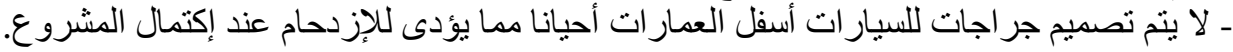

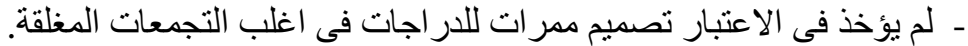

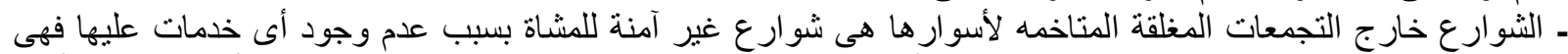

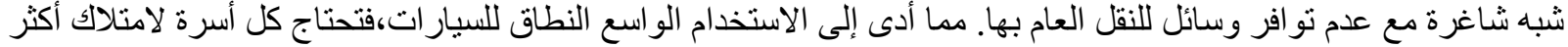

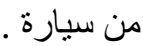

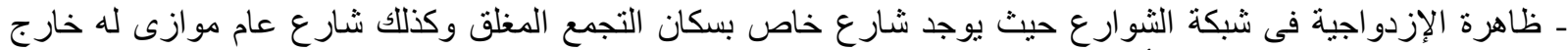

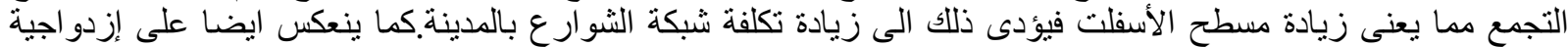

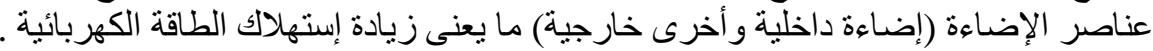

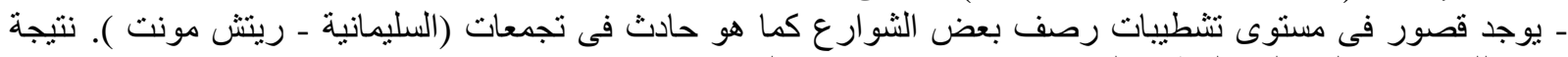

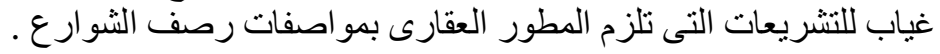

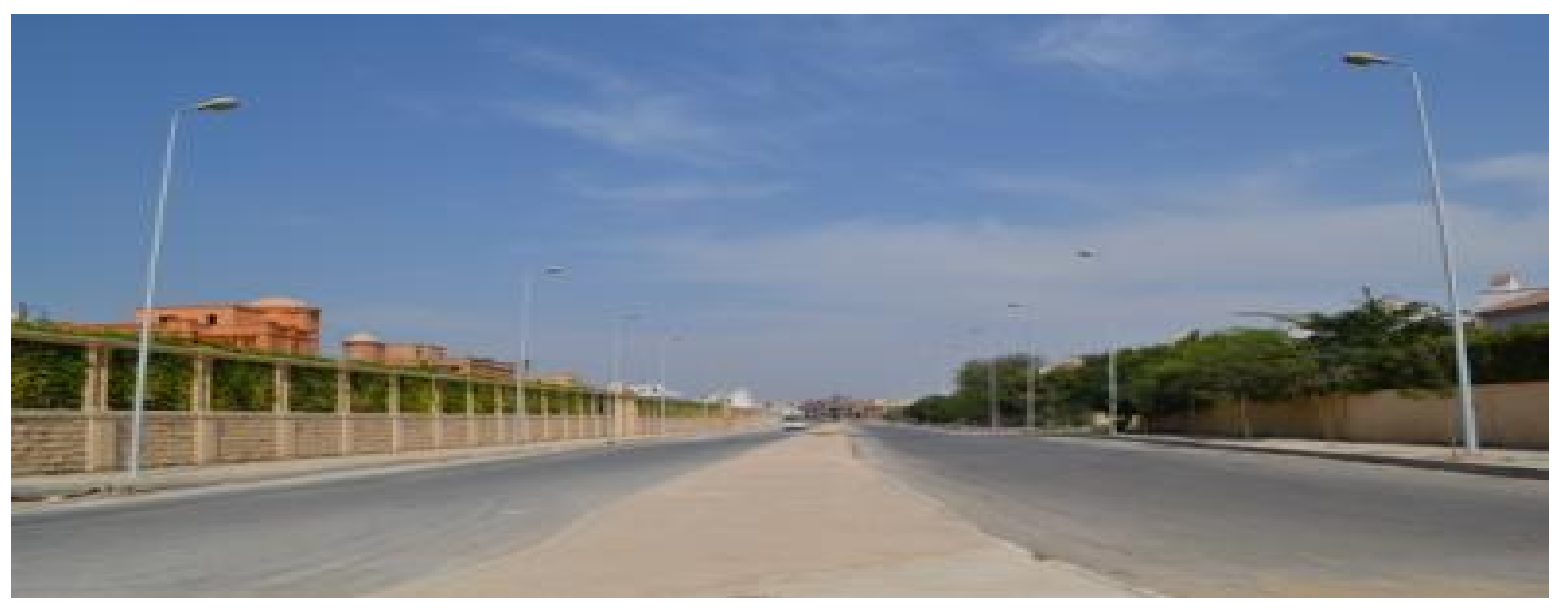

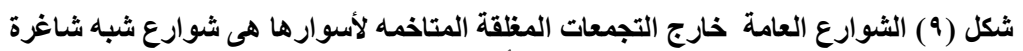

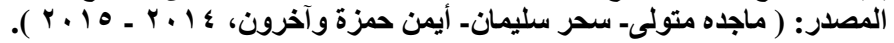

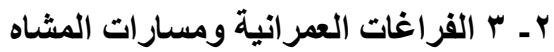

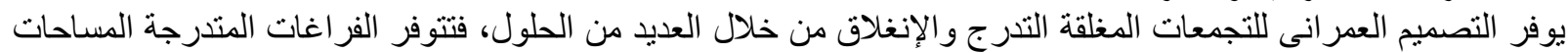

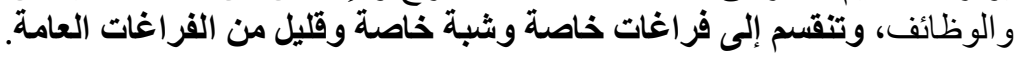

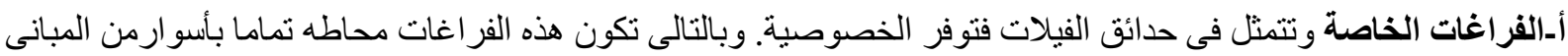

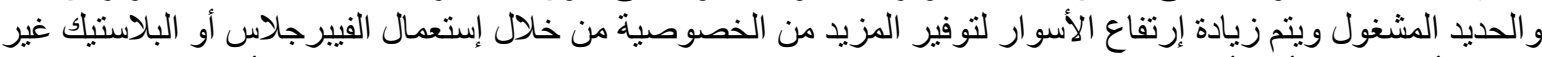

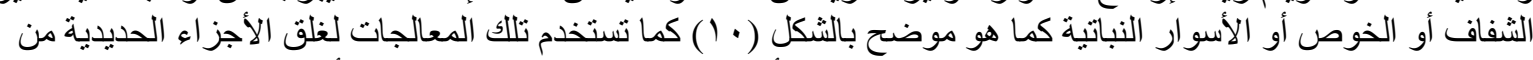

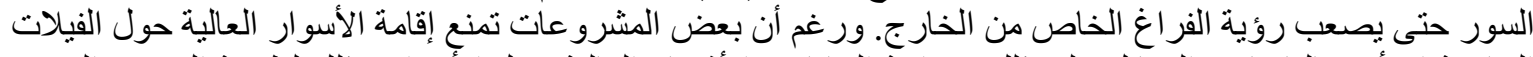

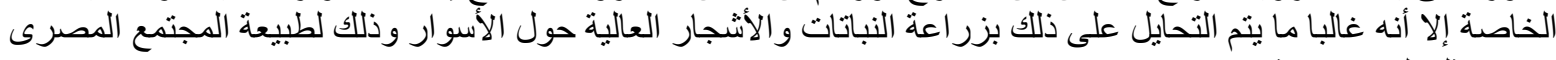
حيث تمثل الخصوصية إحتياجا إجتماعيا هاما. 
اثر عناصر الطابع العمر انى بالتجمعات السكنية المغلقة على ملامح تشكيل المدن الجديدة "دراسة حالة مدينة الثيخ زايد

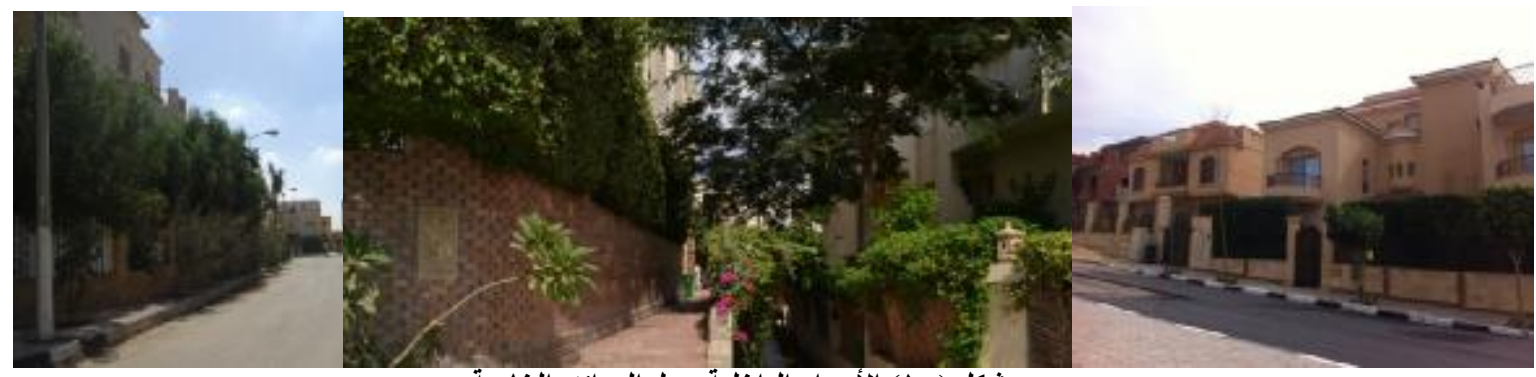

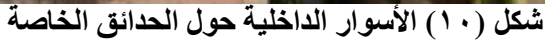

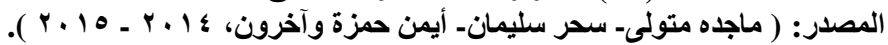

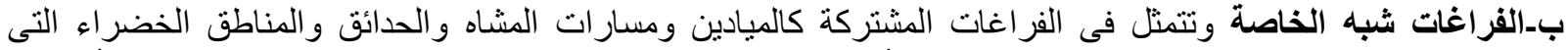

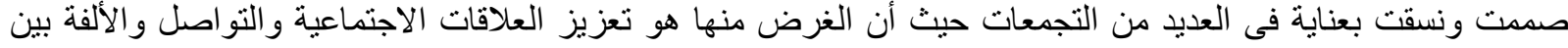

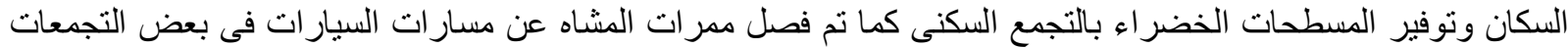

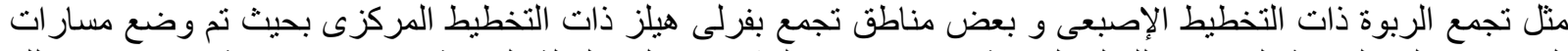

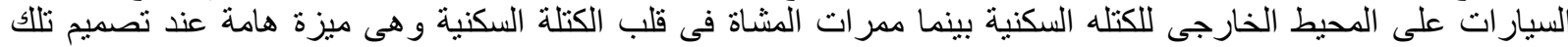

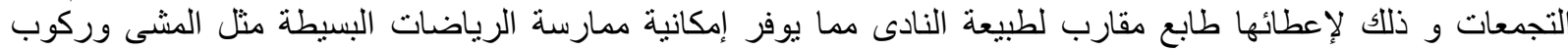

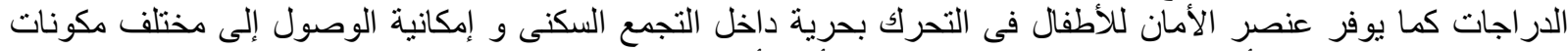

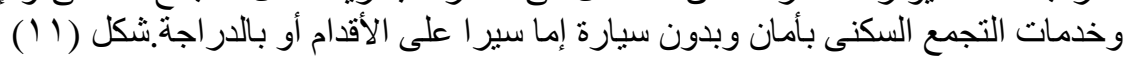
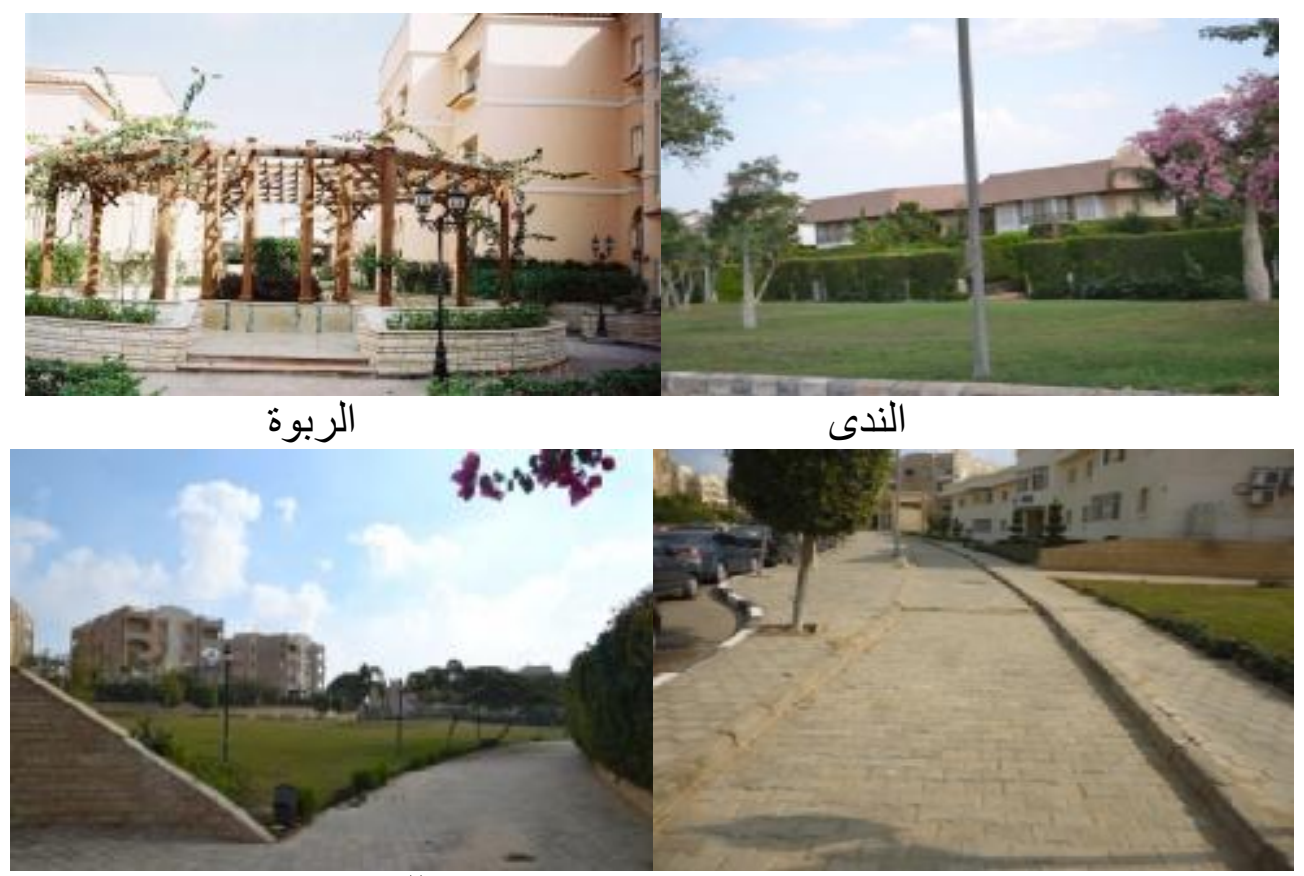

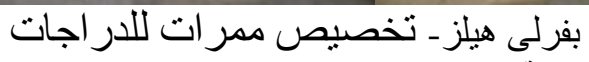

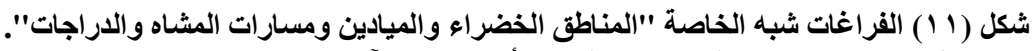

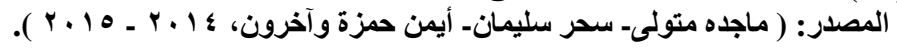

ت

r ـ ك الخدمـ

تتنوع و تتوزع الخدمات بالتجمعات المغلقة حسب احجام هذة التجمعات حيث يتضح أن نوعية ومسطح الخدمات يتناسبان

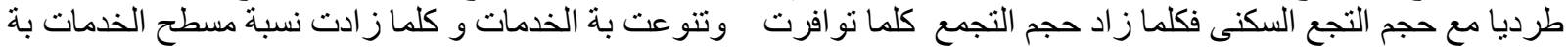




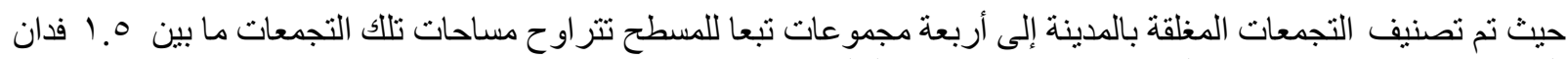

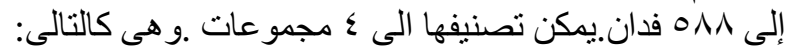

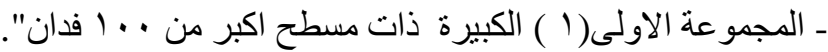

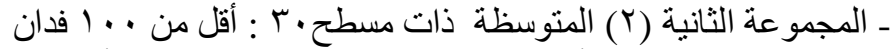

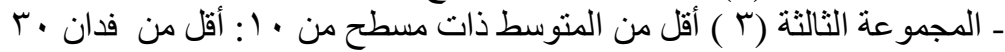

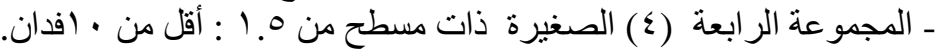

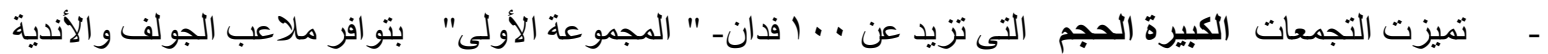

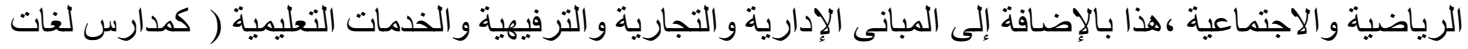

ودولية كما بتجمع بفرلى هيلز وبتجمع الياسمين).

كما بدأ حديثا التوجه نحو إقامة مبانى فندقية داخل نطاق تلك التجمعات السكنية الخاصة كما في تجمع (ويدت تأناون). وجميع

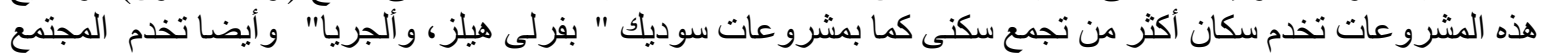

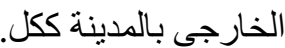

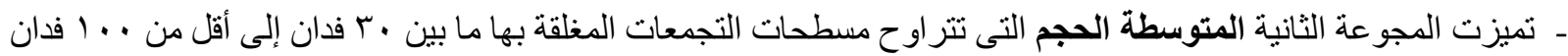
بتو افر الخدمات التجارية و الترفيهية و الرياضية والدية الدينية.

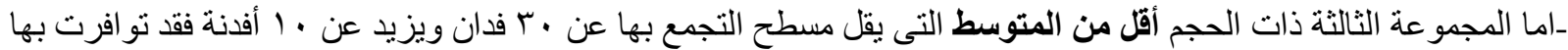

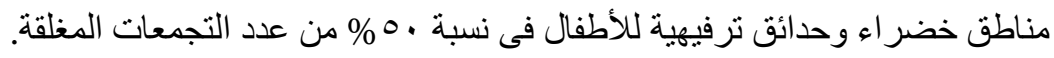

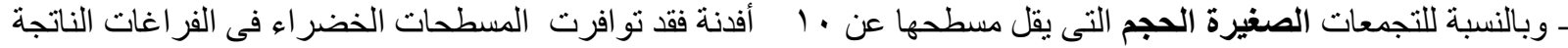
عن تثكيل الكتل كما تو افرت حمامات السباحة فى نسبة • ؛ \% من المينى كمبوند، بينما لا تتو افر خدمات فى النسبة الباقية .

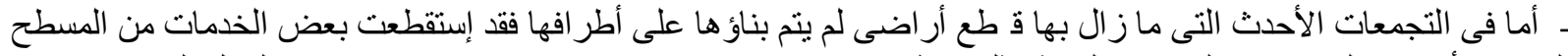

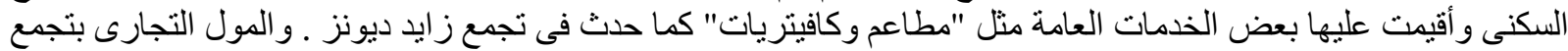

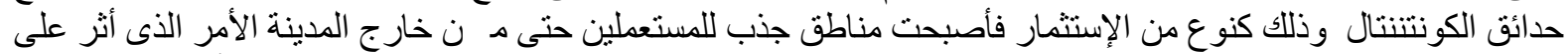

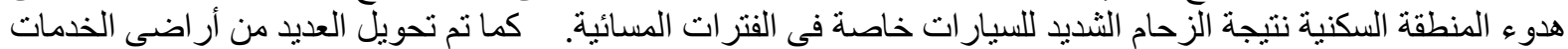

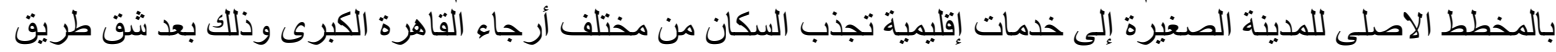

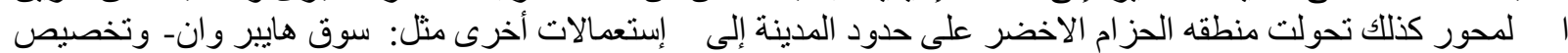

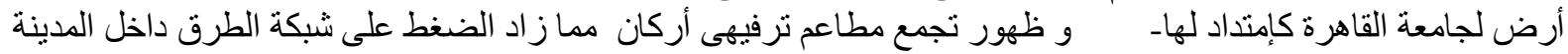

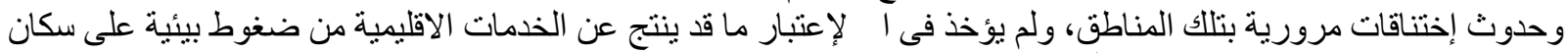

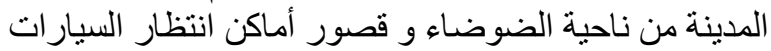


اثر عناصر الطابع العمر انى بالتجمعات السكنية المغلقة على ملامح تشكيل المدن الجديدة "دراسة حالة مدينة الثيخ زايد
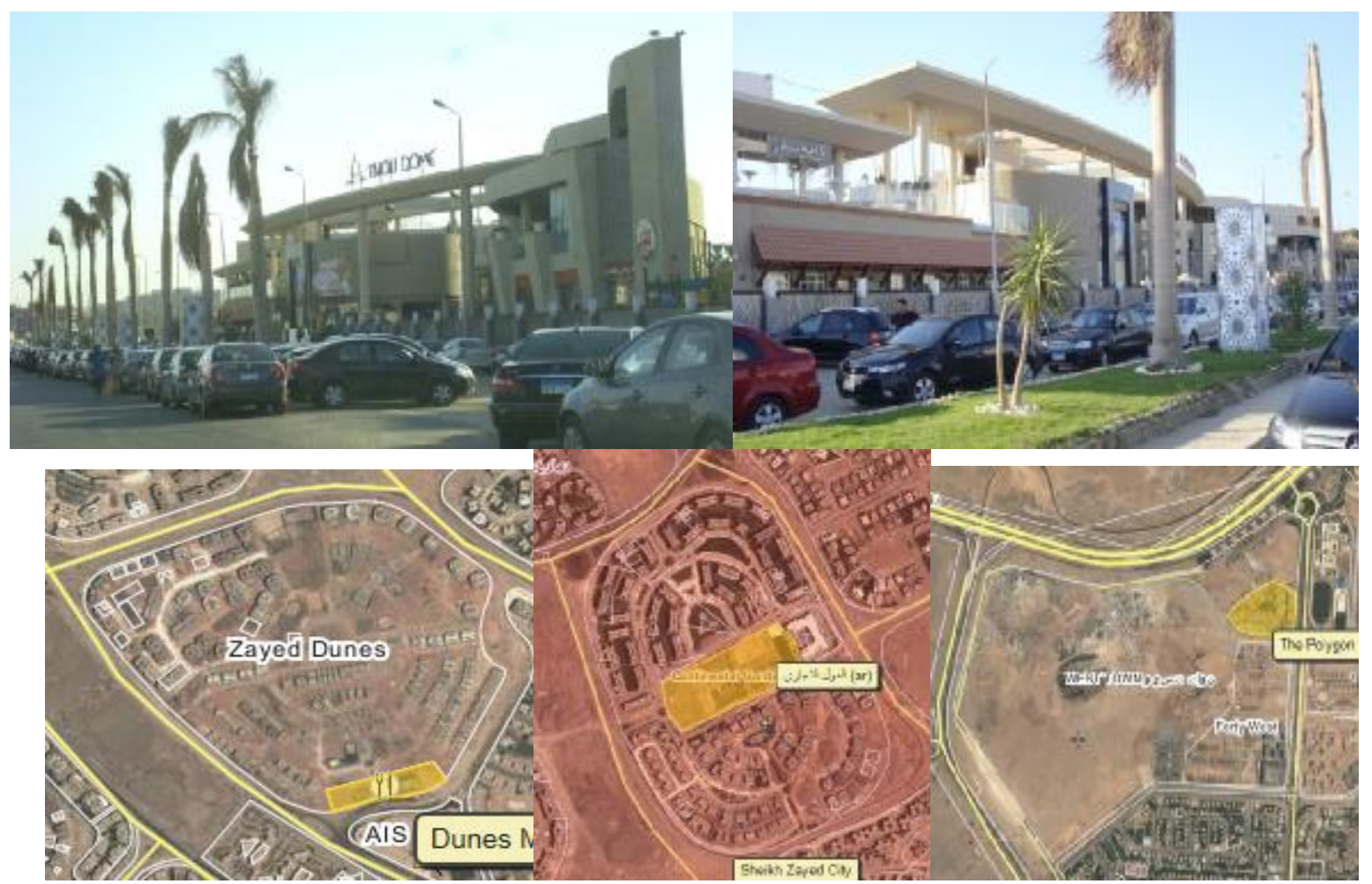

ويست تاون

حدائق الكونتنتتال

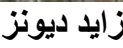

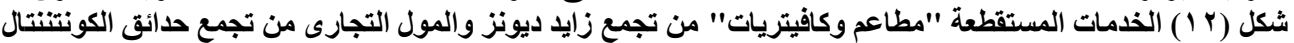

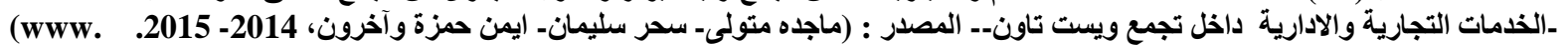
google earth/historical imagery/(2017)

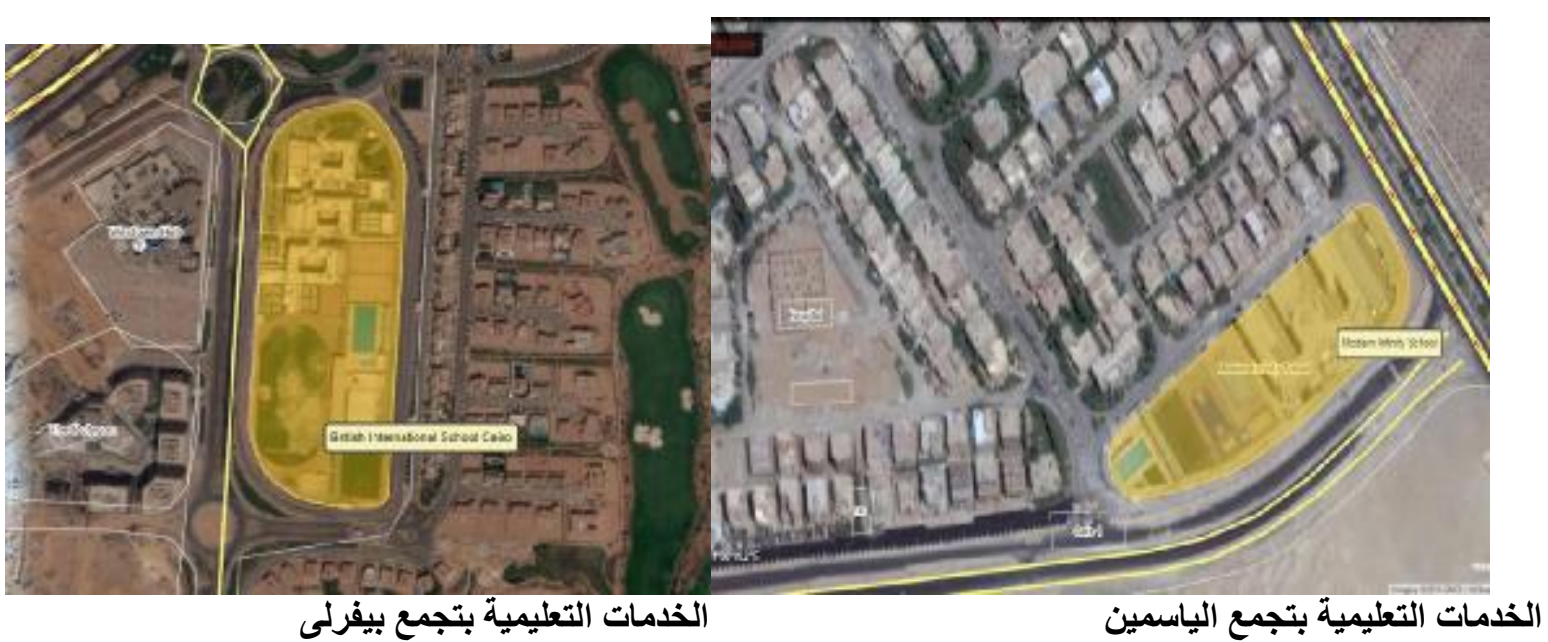

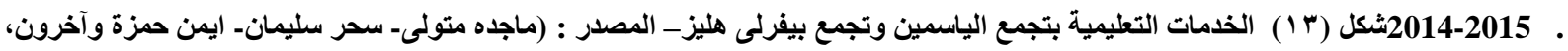
(www. google earth/historical imagery/(2017) 


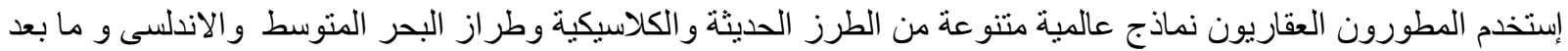

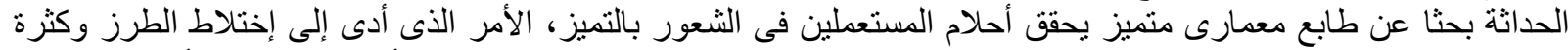

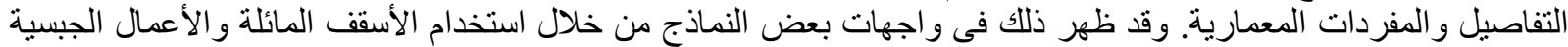

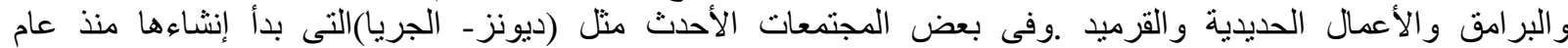

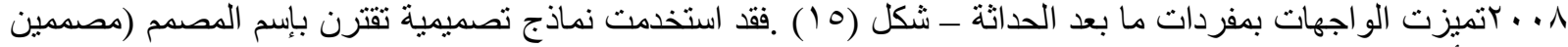

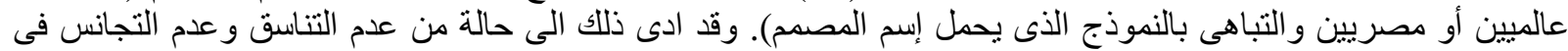

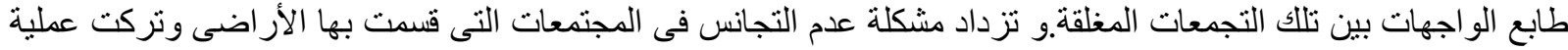

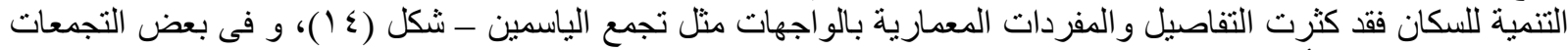

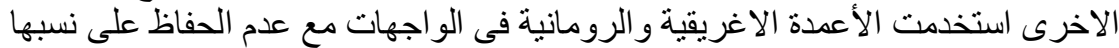
ـ كما ظهرت بعض المبالغات فى استخدام مفردات العمارة الكالاسيكية (الأعمدة- البرامقـ- القرميد- الأعمال الجبسية)

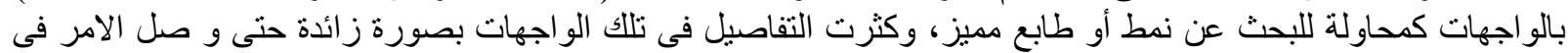

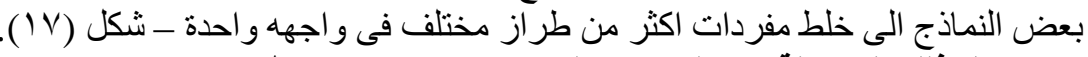

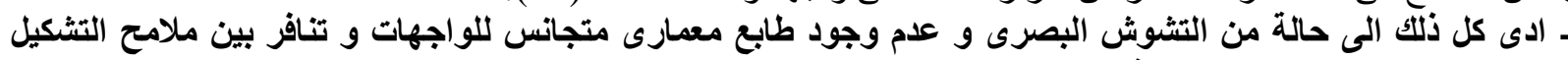

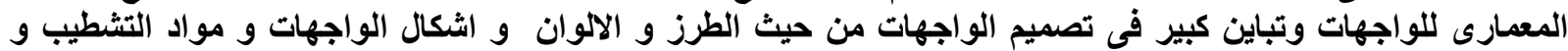

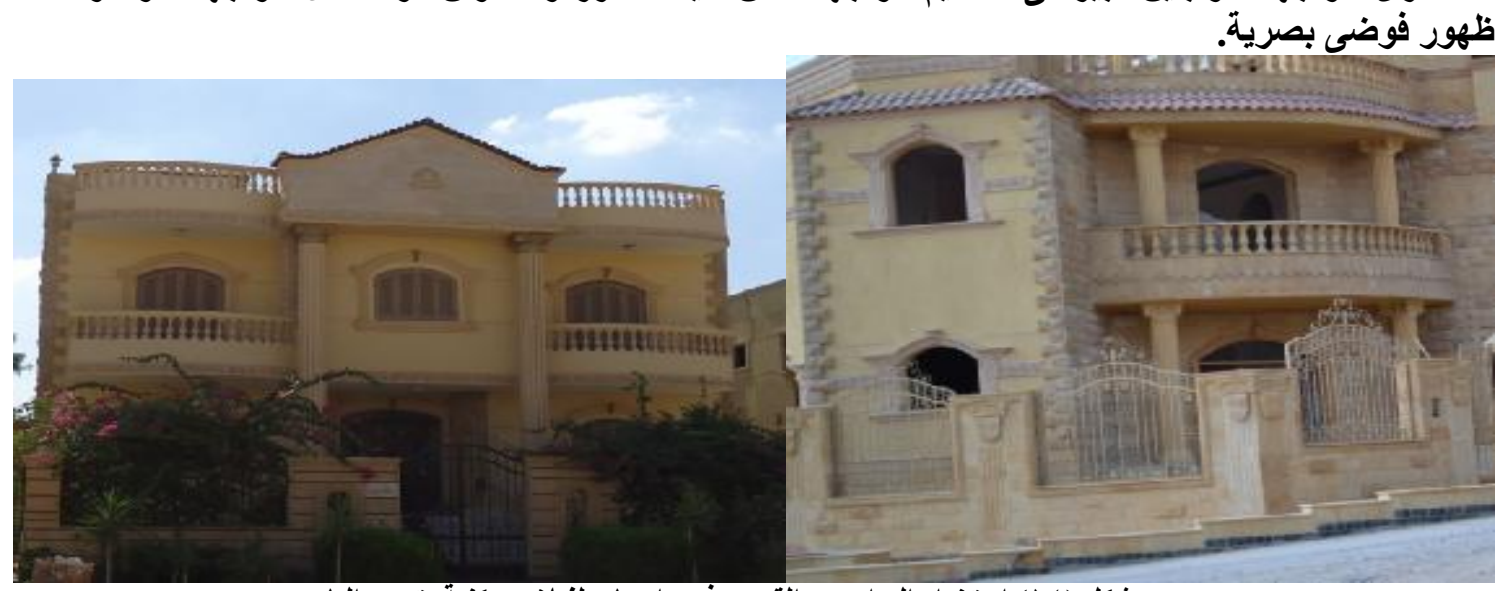

شكل ( ) ( ) إستخدام البرامق و القرميل في واجهات لقيلات سكنية بتجمع الياسمين

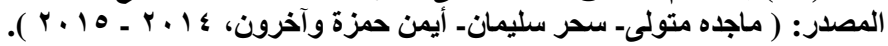

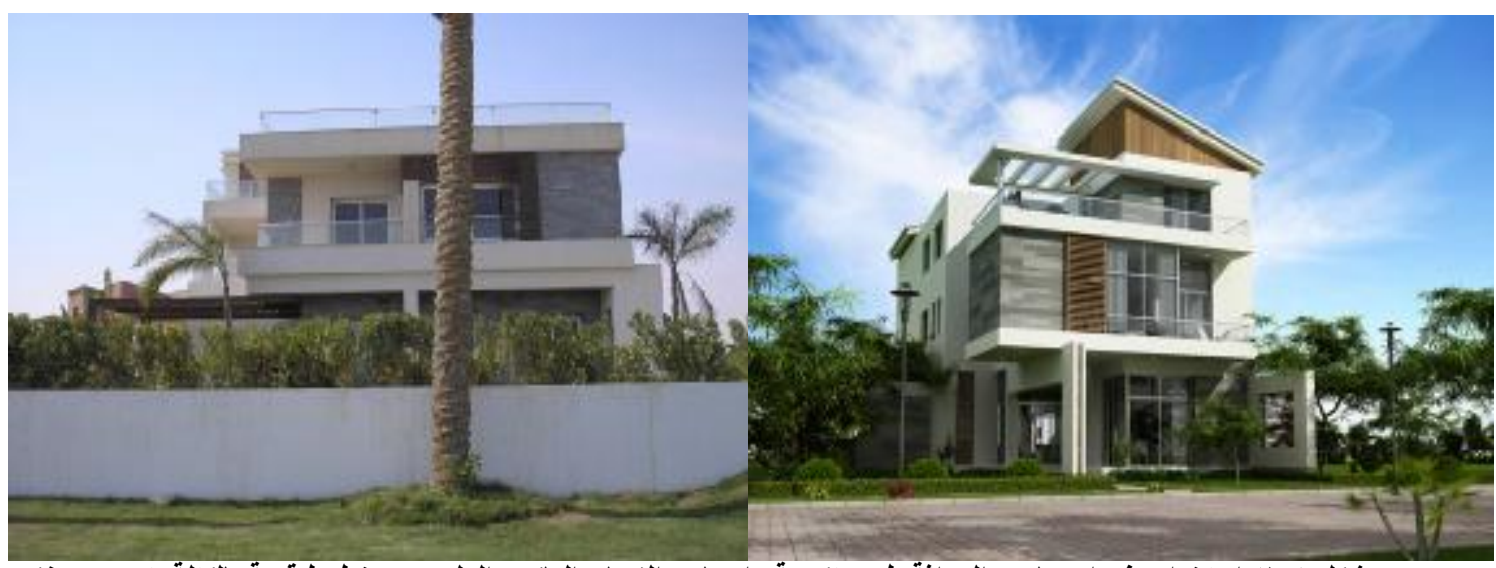

شكل (0) استخدام مفردات ما بعد الحداثة طوب تكسية واجهات، الزجاج العاكس الملون مع خطوط قوية بالكتلة بتجمع ديونز

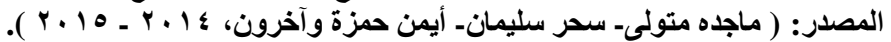


اثر عناصر الطابع العمر انى بالتجمعات السكنية المغلقة على ملامح تشكيل المدن الجديدة "دراسة حالة مدينة الثيخ زايد
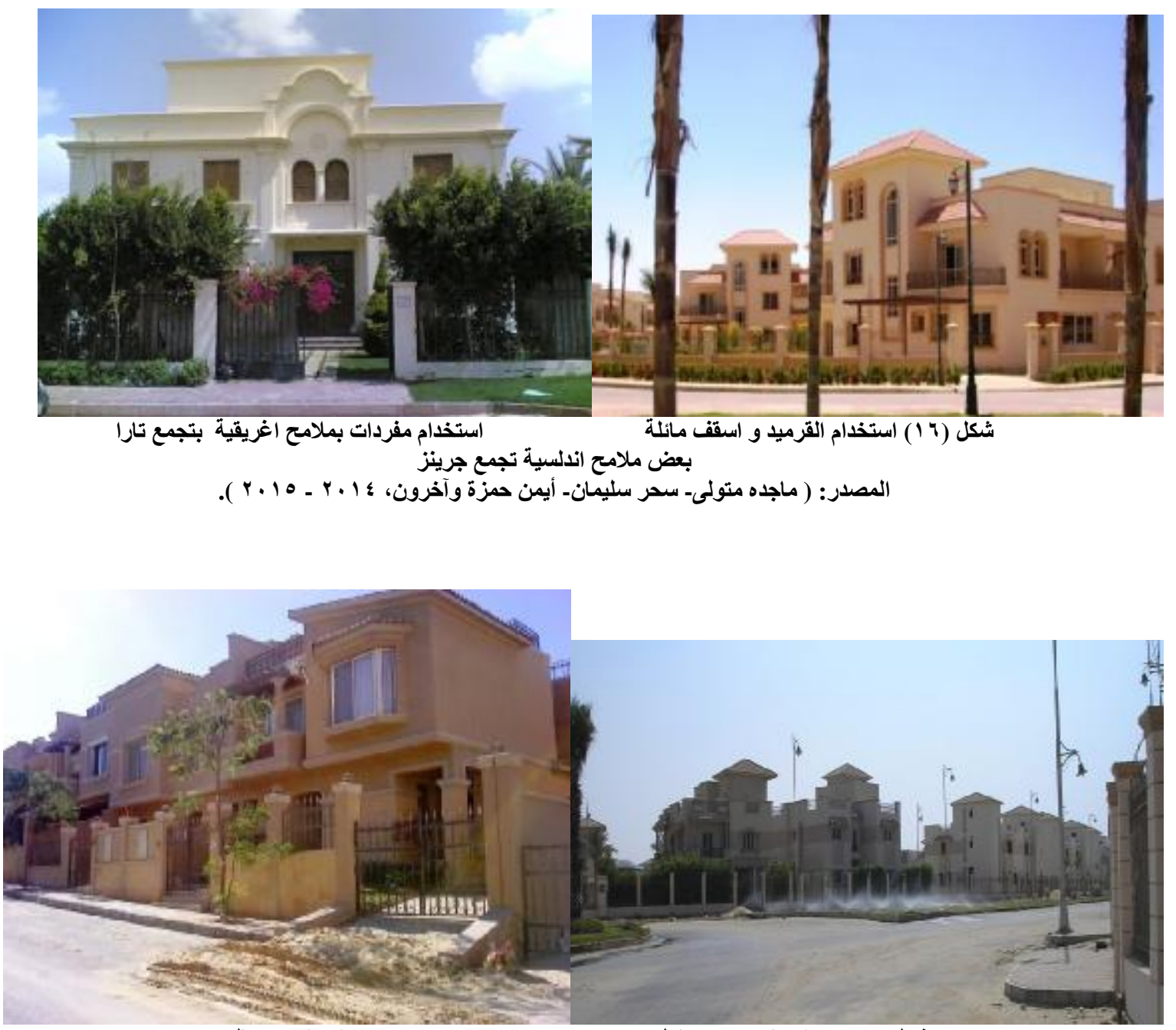

واجهات رويال سيتحي

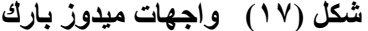

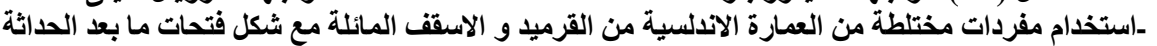

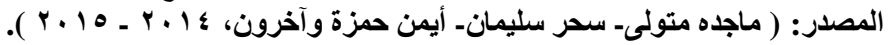

ـ تنوعت إرتفاعات المبانى فى التجمعات المغلقة فقى الفيلات و التناون والتوين هاوس تراوحت الارتفاعات بين دورين إلى ثلاثية

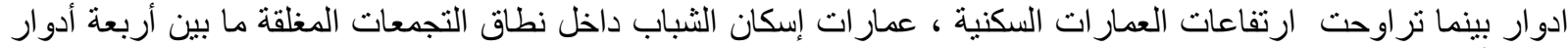
إلى ألى أدو ار.

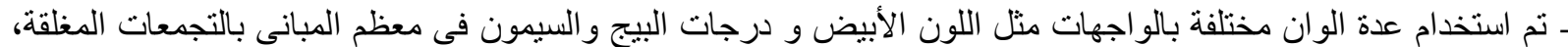

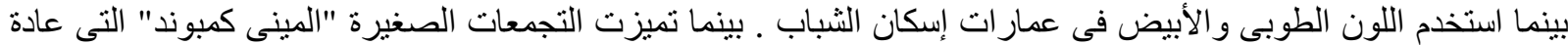

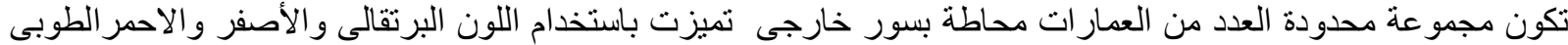

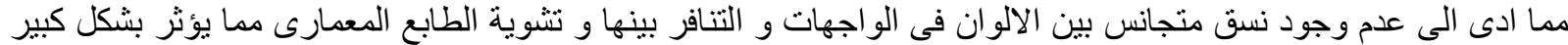
على المشهد الحضرى للمدينة. 


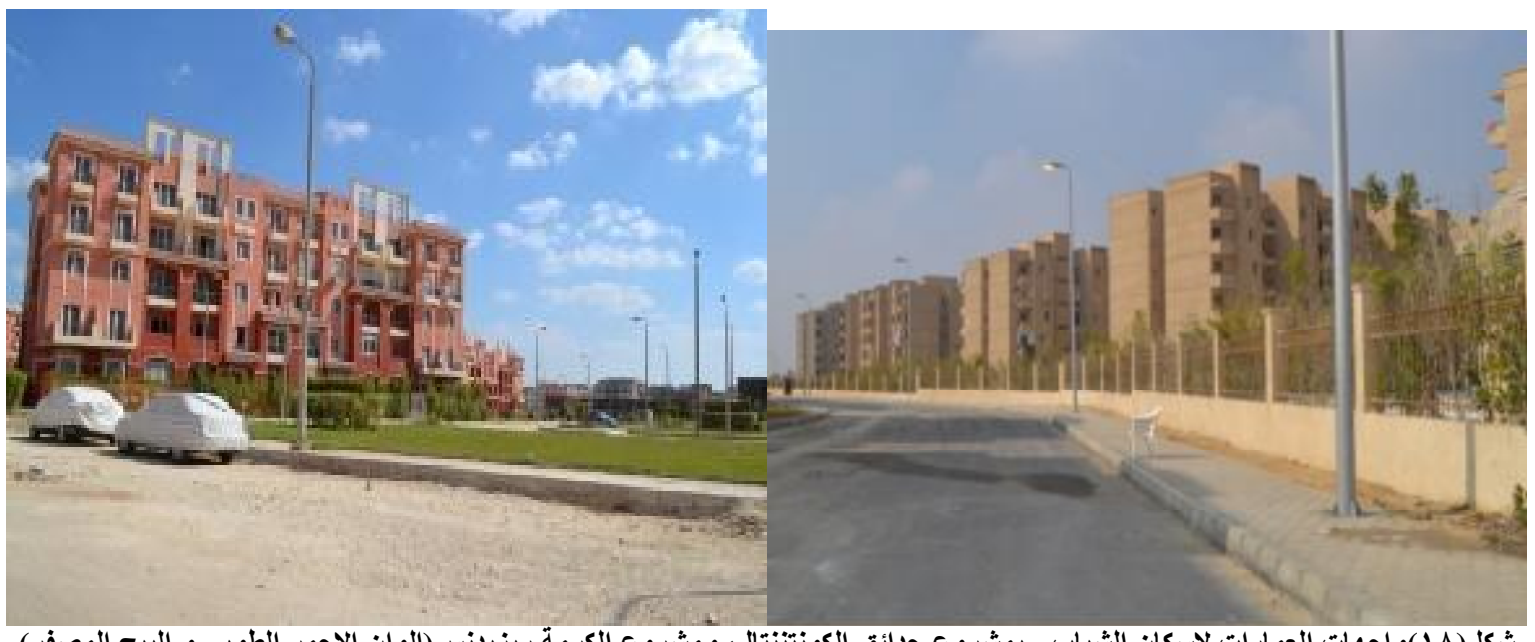

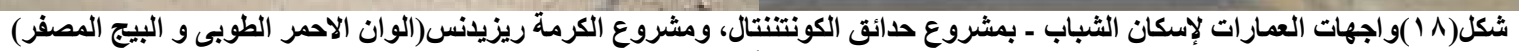

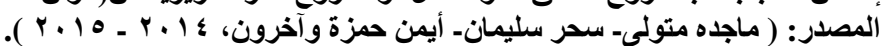

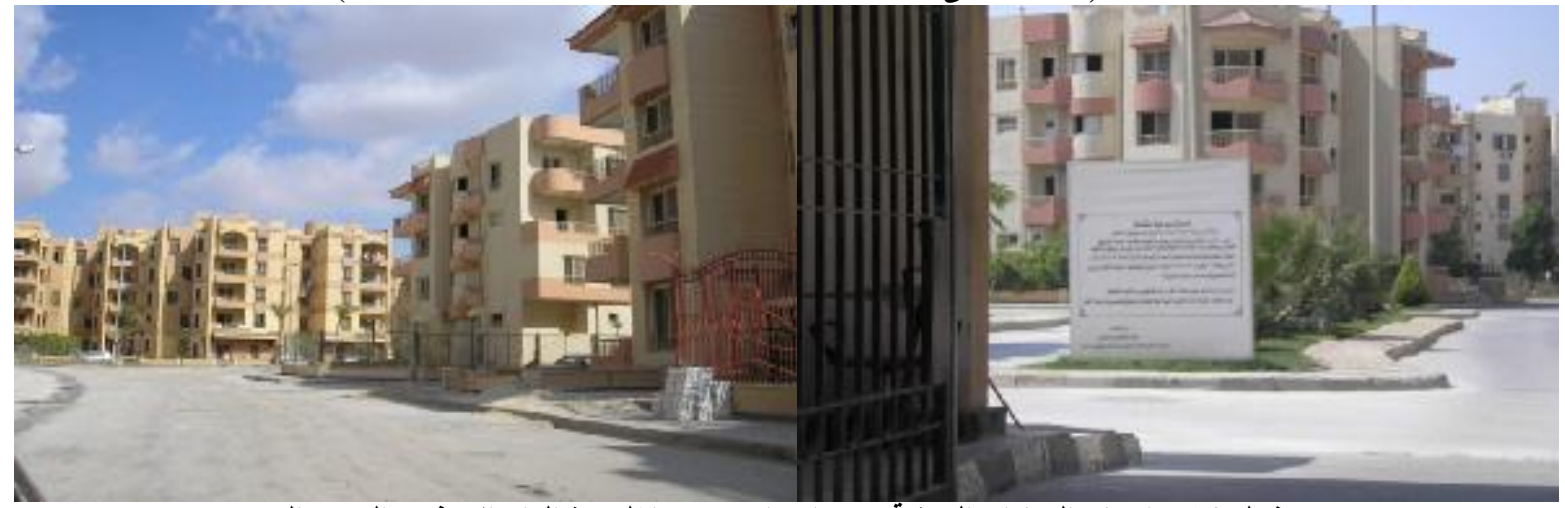

شكل(9 1 ) واجهات العمارات السكنية تجمع اوبرا سيتى- تداخل عدة الوان الاصفر و البيج و الروز

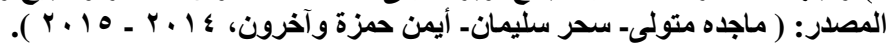

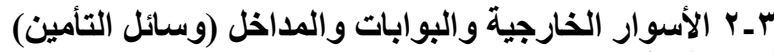

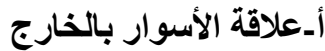

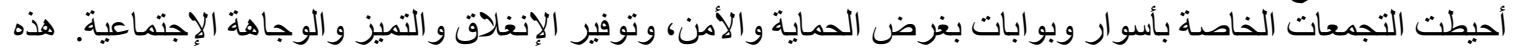

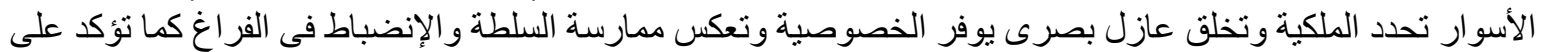

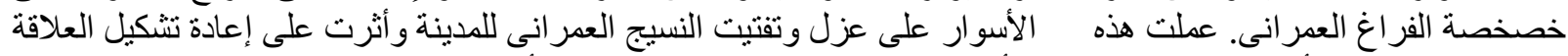

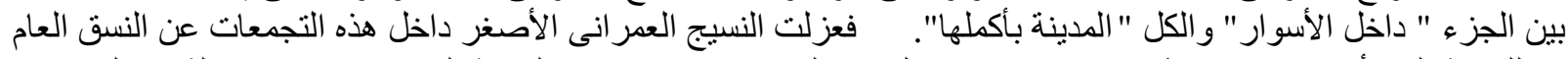

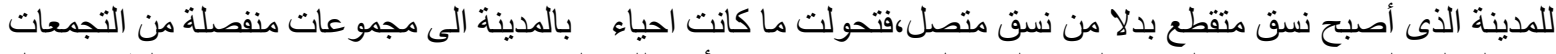

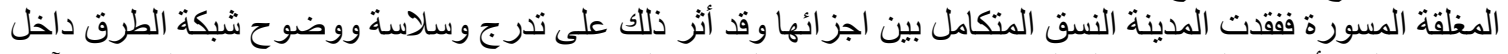

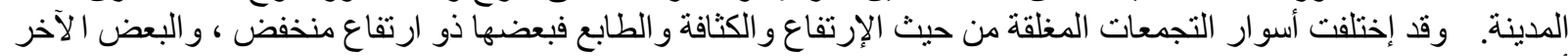

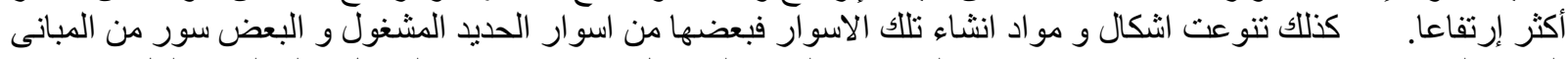

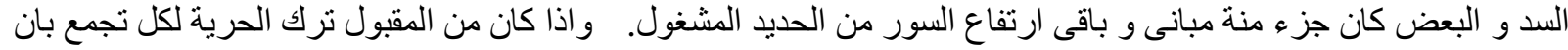

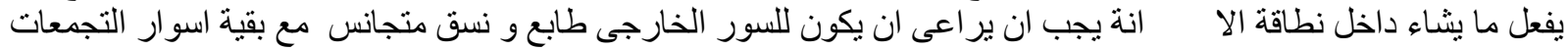

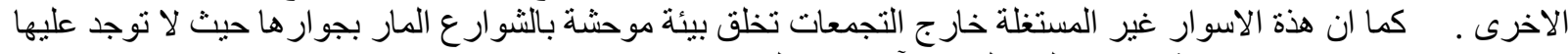

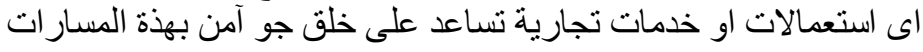


اثر عناصر الطابع العمر انى بالتجمعات السكنية المغلقة على ملامح تشكيل المدن الجديدة "دراسة حالة مدينة الثيخ زايد

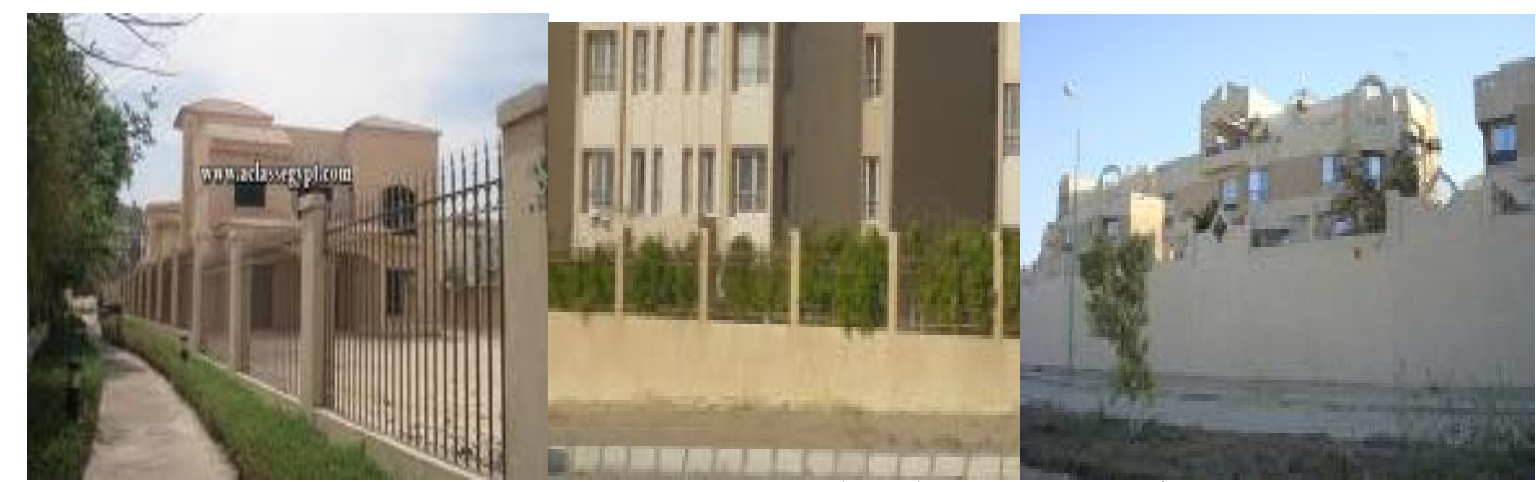

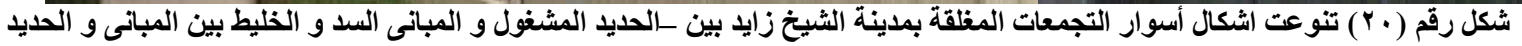
المشغول

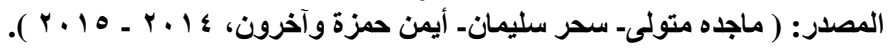

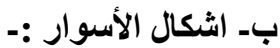

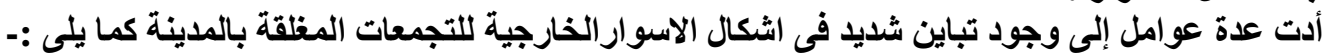

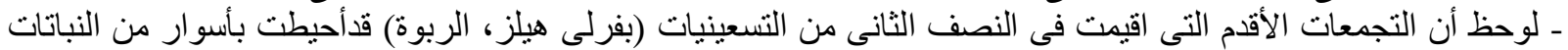

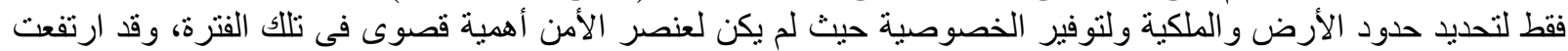

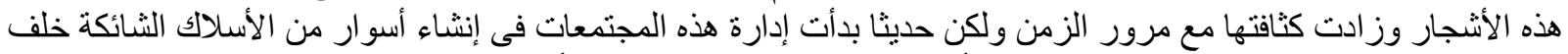

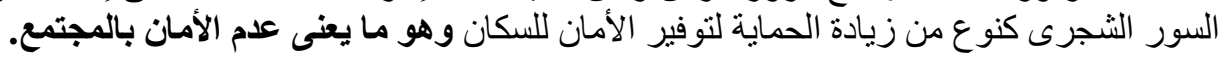

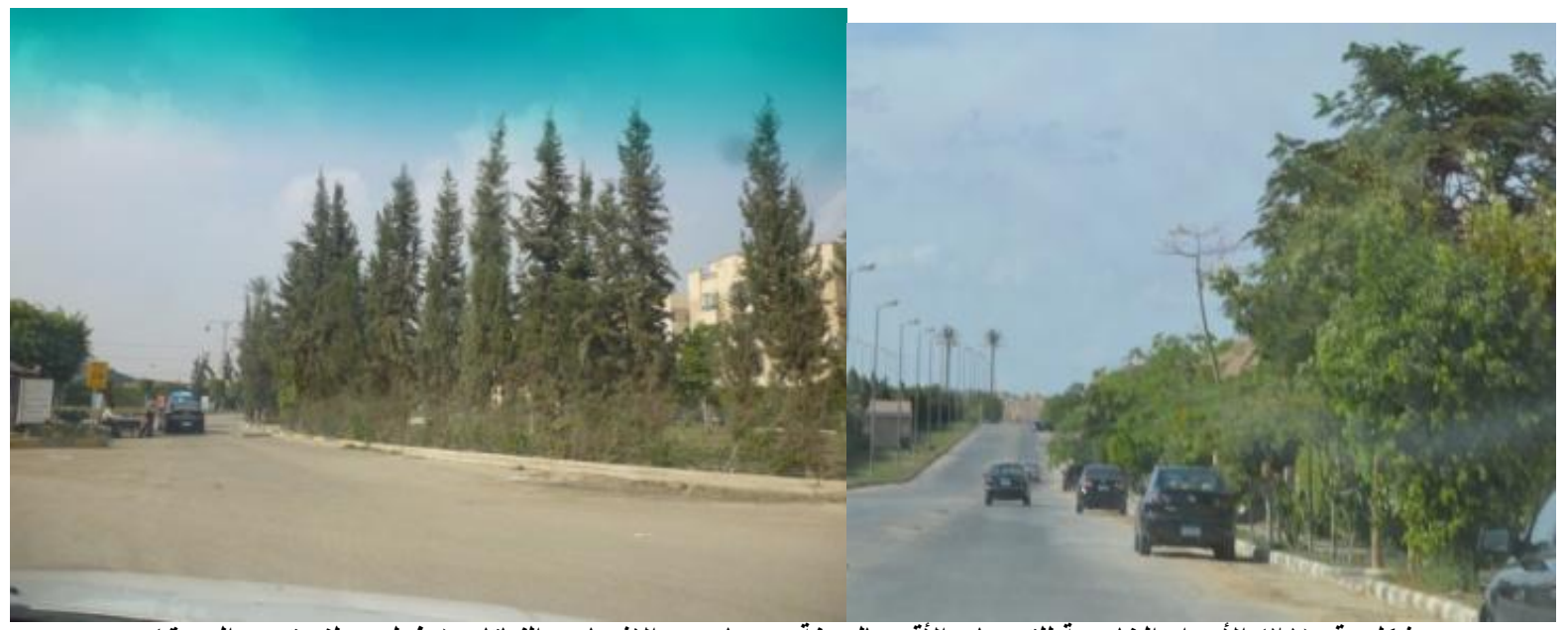

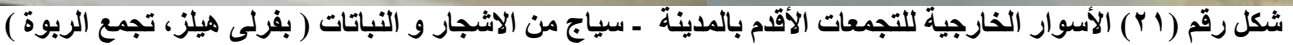

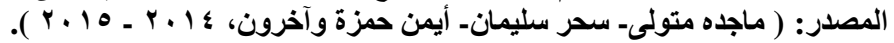

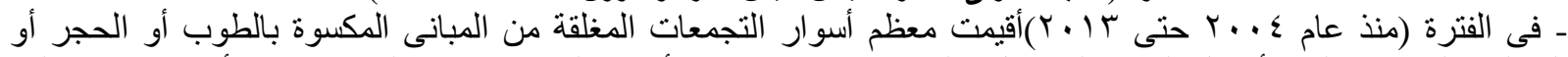

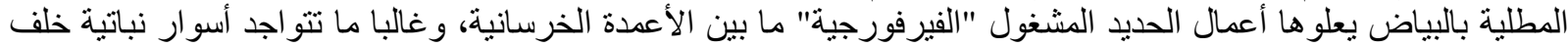
الأسوار الخرسانية.وقد إختلفت الأسوار من حيث الاشكال والإرتفاعات و أضيفت وحدات للإضاءة بأنثكال مختلفة كعنصر

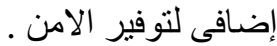

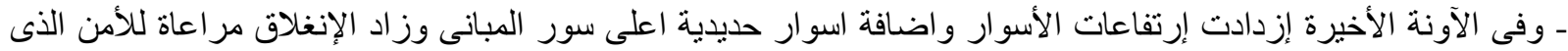

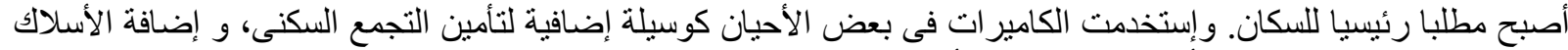

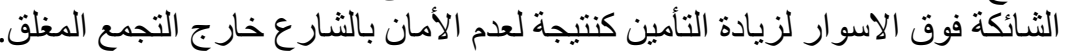

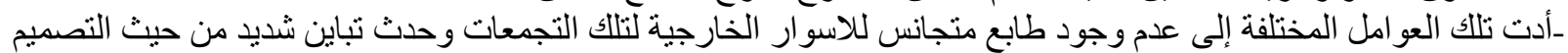

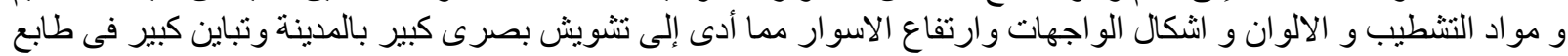

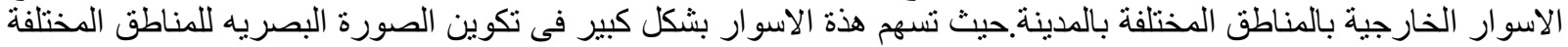




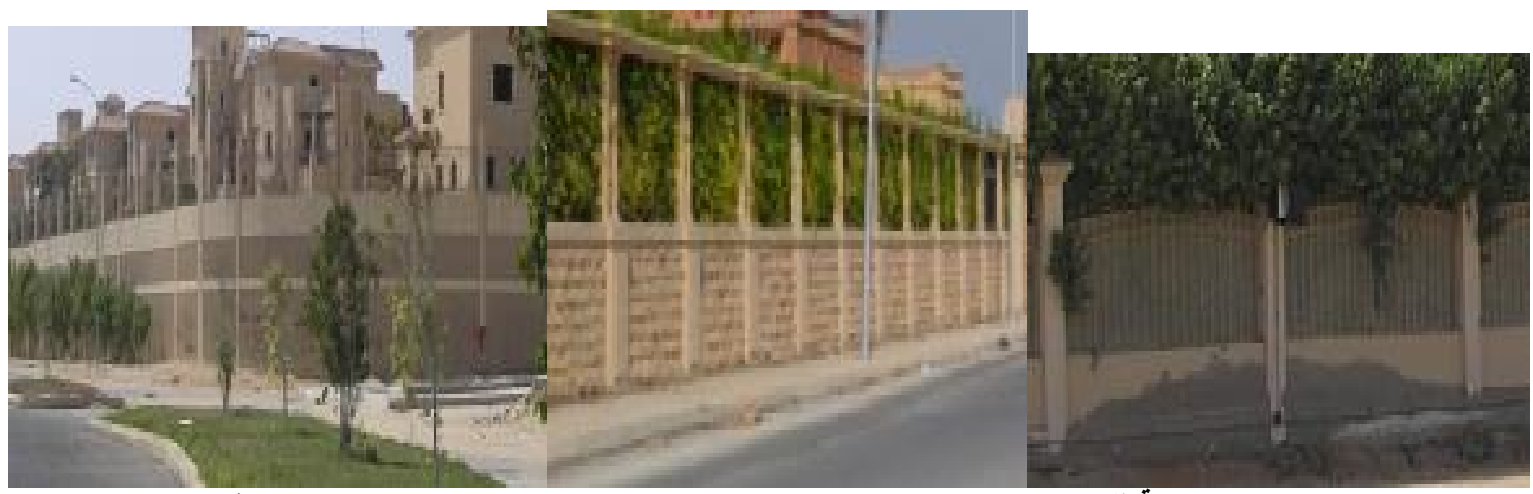

سور تجمع جرينز

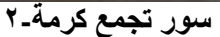

شكل رقم (r r) الأسوار الخارجيةً للتجمعات الأحلث بالمدينة ـ الأسوار الخارجية للتجعات الاحثث بالمدينة ازدياد الارتفاعات و اضافة اسوار حديدية

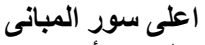

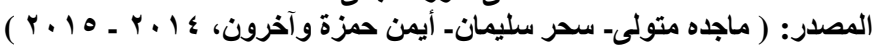

ج-"'البوابات والمداخل" اختلف تصميم البو ابات من تجمع إلى آخر وأخذت طرز وأشكال مختلفة معبرة عن: مدى التميز و الوجاهة الاجتماعية ـ شدة

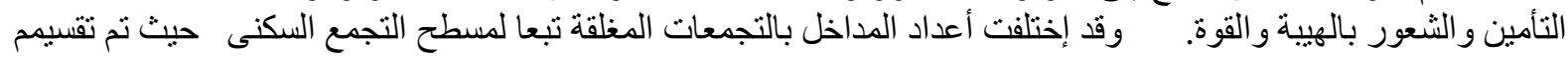

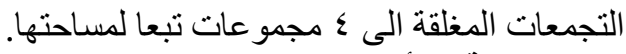

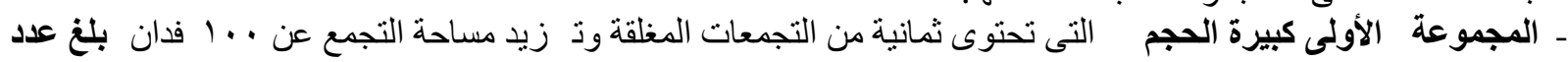

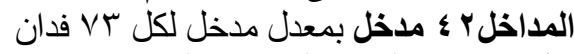

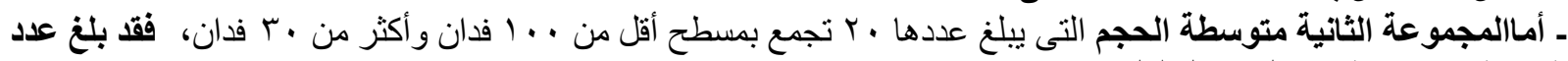

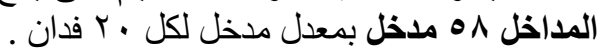

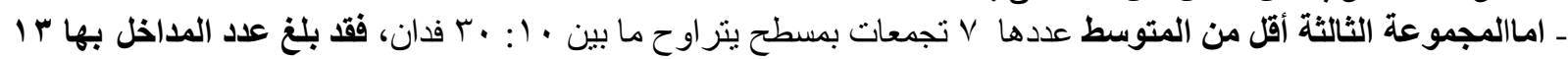

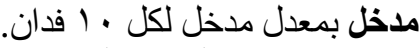

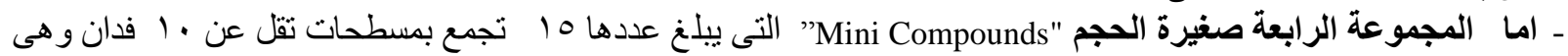

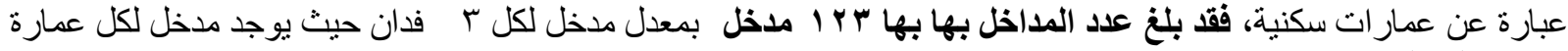

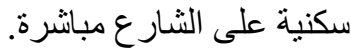

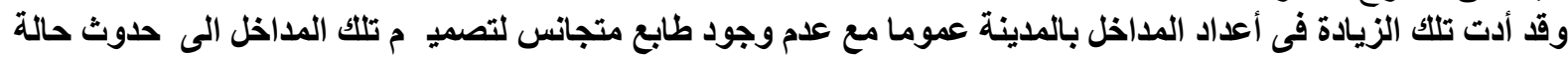

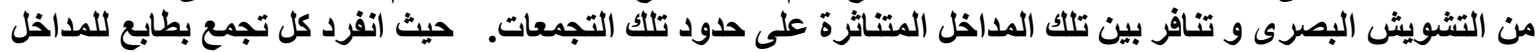

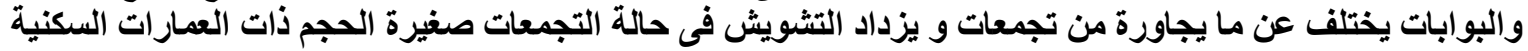

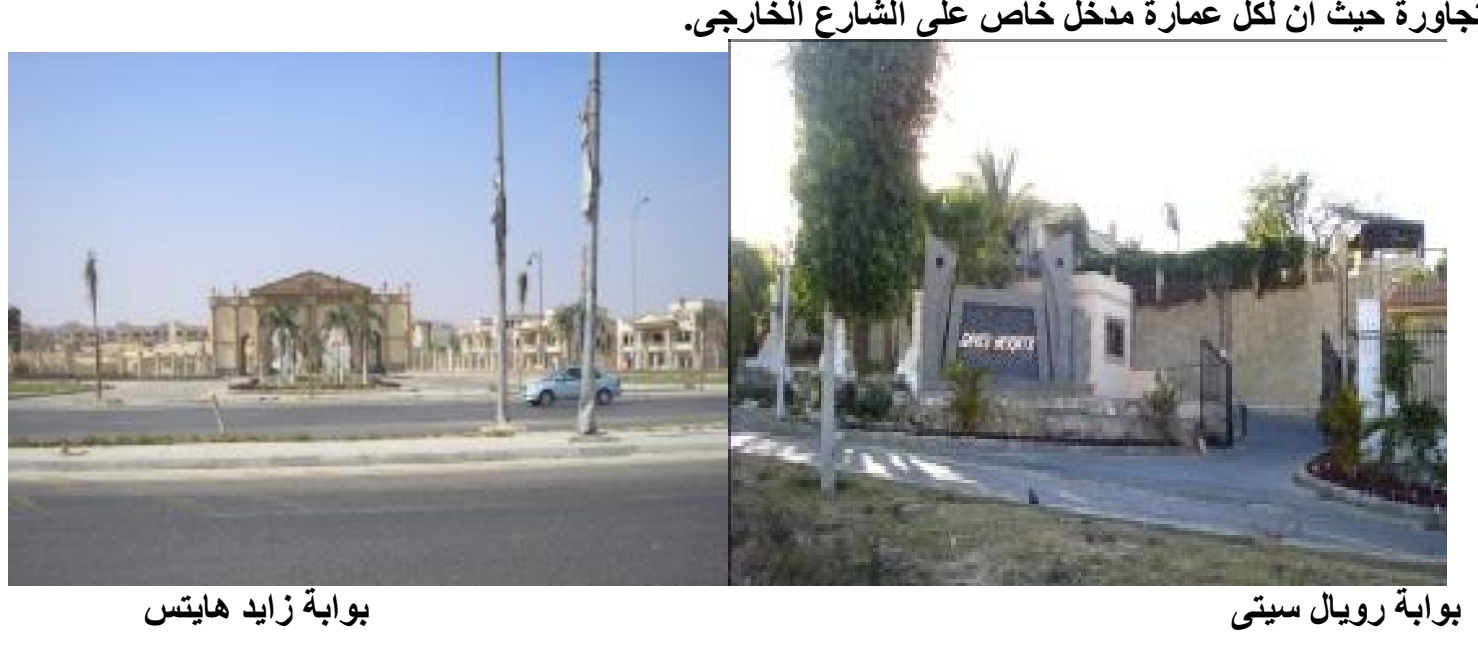


اثر عناصر الطابع العمر انى بالتجمعات السكنية المغلقة على ملامح تشكيل المدن الجديدة "دراسة حالة مدينة الثيخ زايد
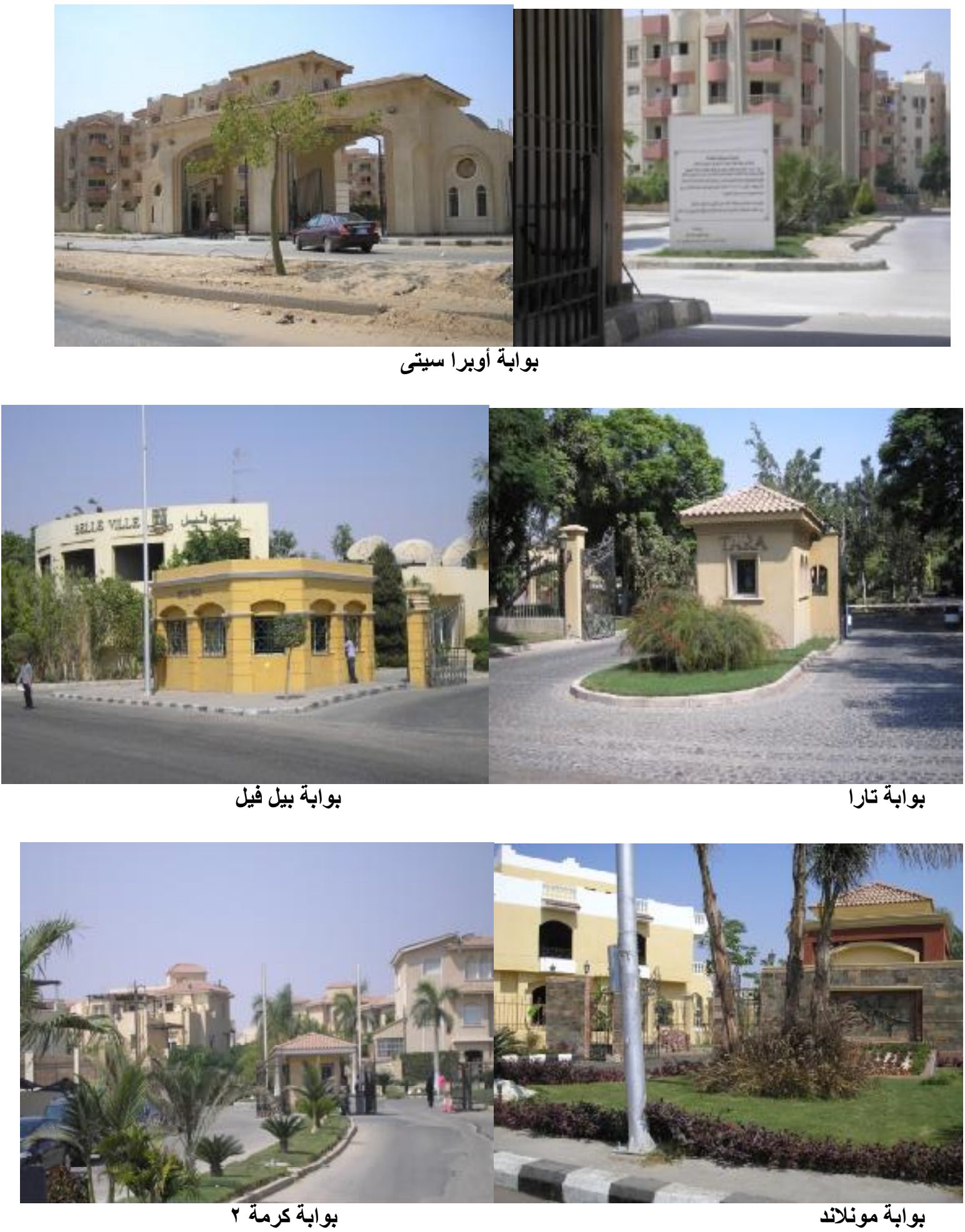

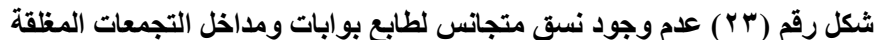

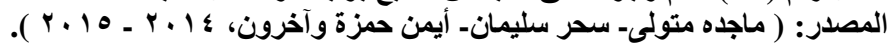

** النتائج :- من خلال التحليلات السابقة خلصت الدراسة للنتائج التالية:- 


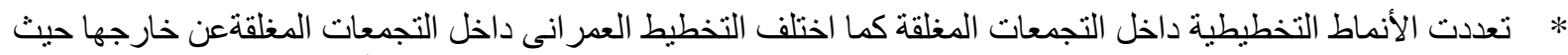

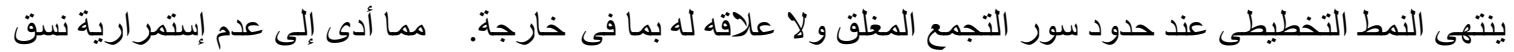

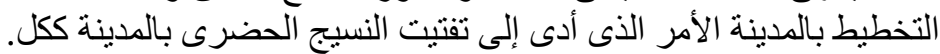

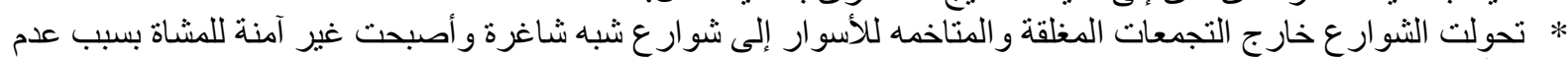

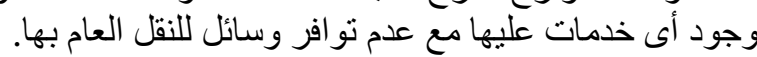

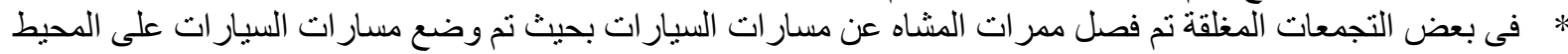

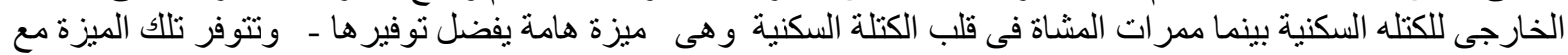

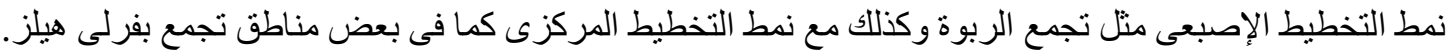

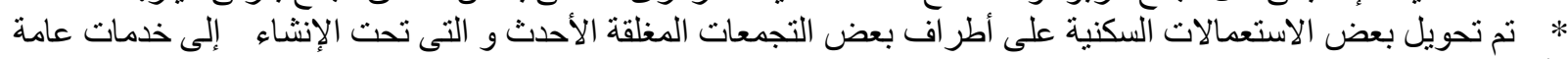

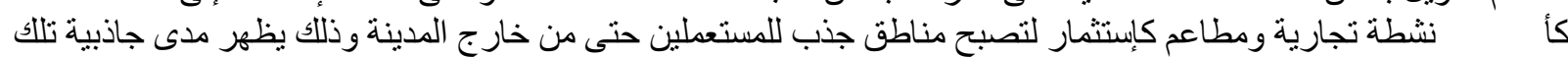

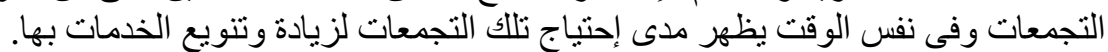

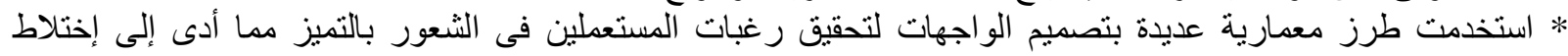

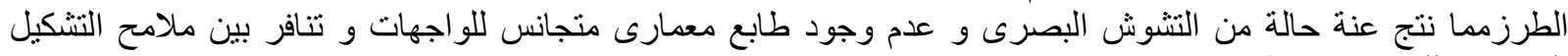

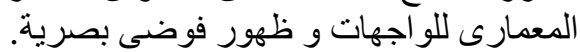
* عدم تجانس فى طابع اسو ار التجمعات المغلقة من حيث التصميم و مو اد التشطيب و الالو ان و اثث كال الو اجهات وارتفاع الاسو ار. * عدم وجود نسق متجانس وطابع يميز تصميم بوابات مداخل التجمعات مما أدى الى تشويش بصرى و الى تنافر بين تلك

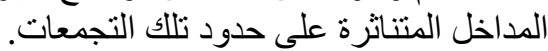

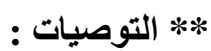

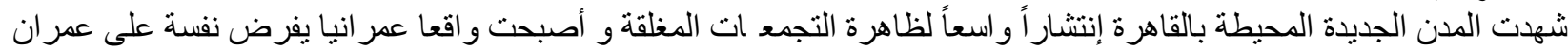

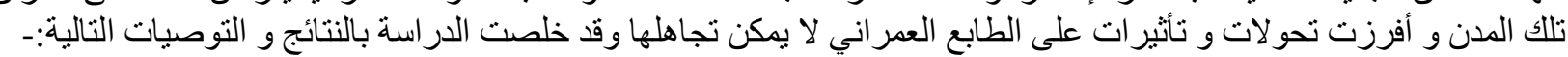

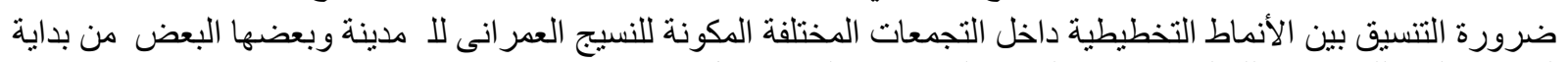
المخطط العام للمدينة و ذلك لمنع تقتييت النسيج الحضرى بلنية بالمدينة ككل .

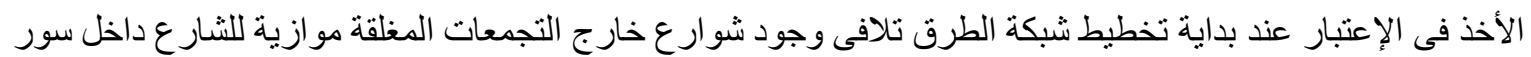

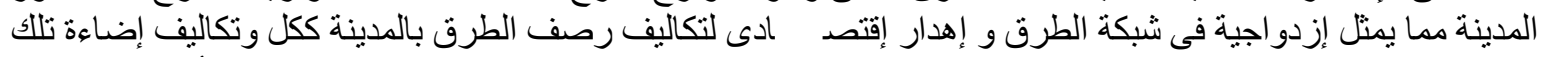

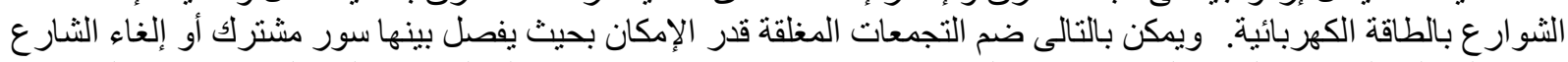

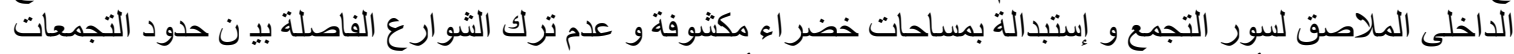

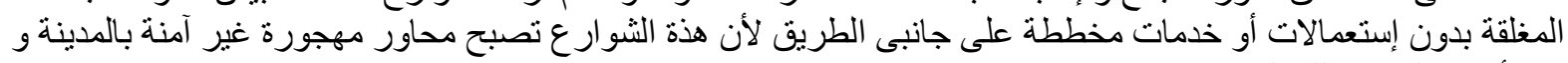

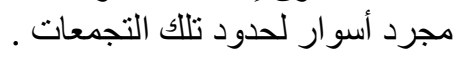

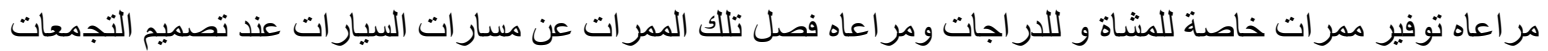

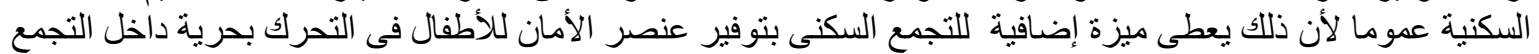

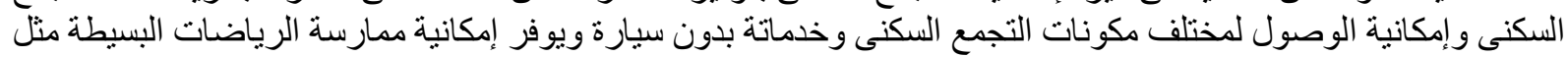

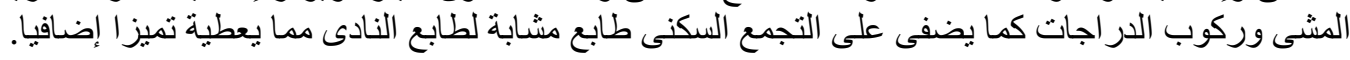

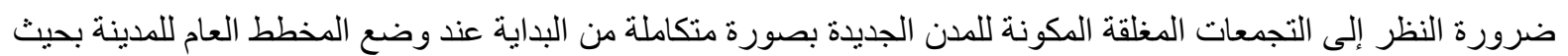

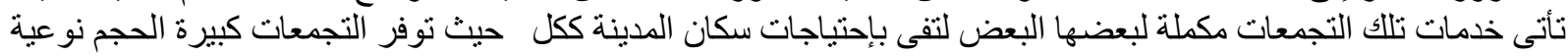

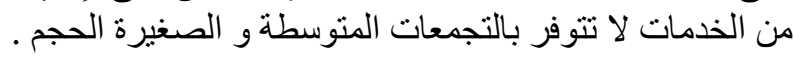

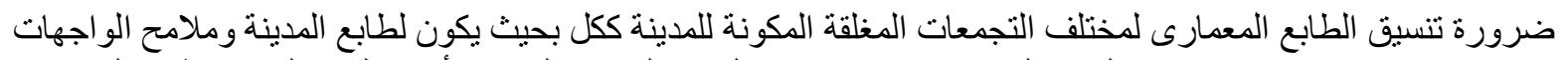

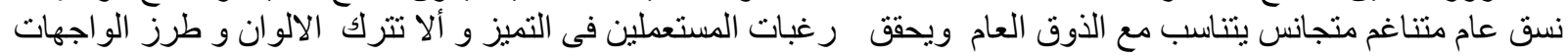

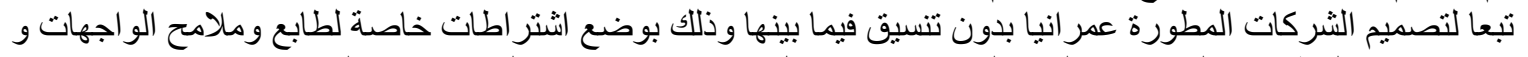

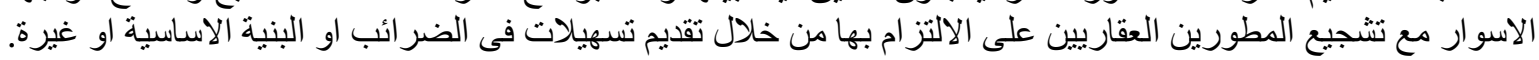

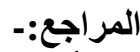

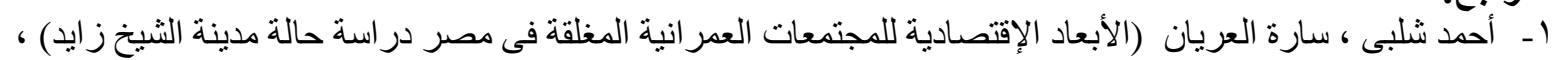

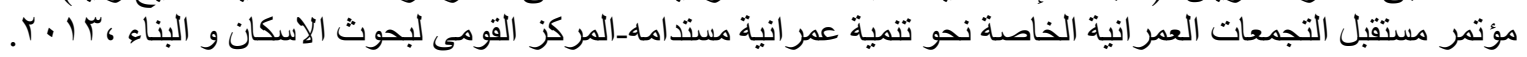




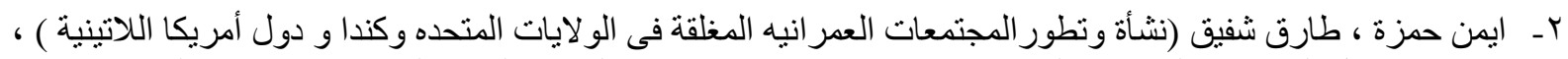

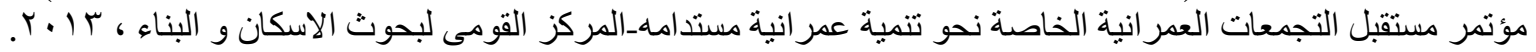

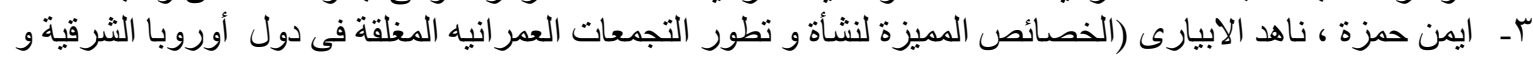

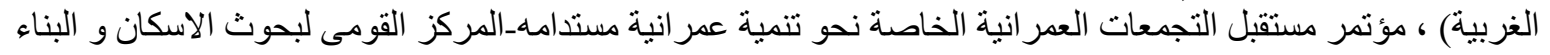
r.

$$
\text { ع ـ أيمن رجب عبد البّ الر اضى محمود ـ شوكت محمد لطفي القاضي ـ حازم عبد العظيم حماد. }
$$

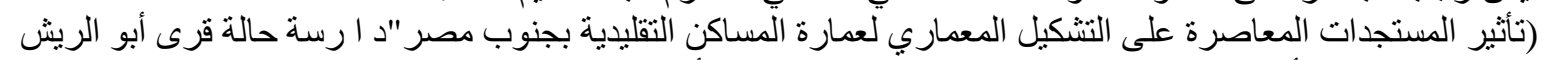

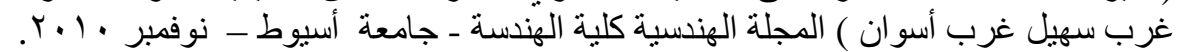

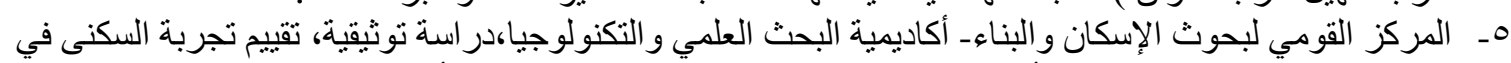

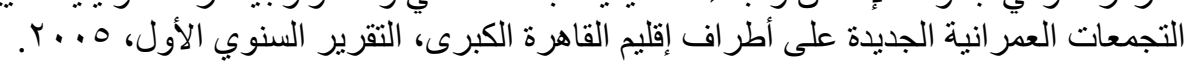

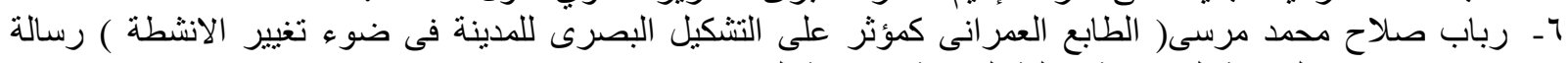

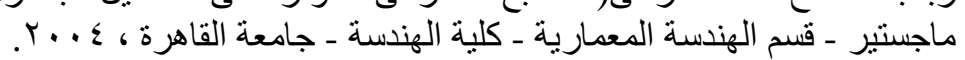

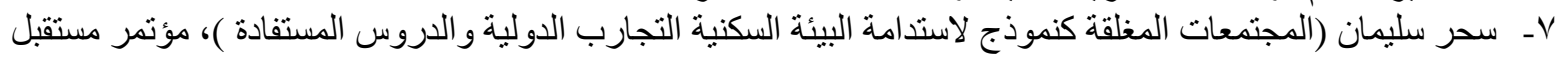

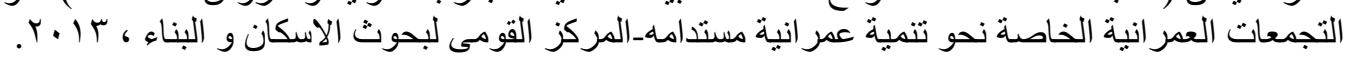

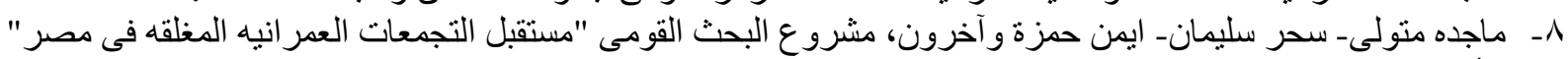

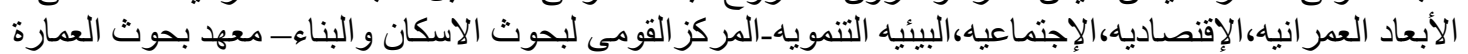

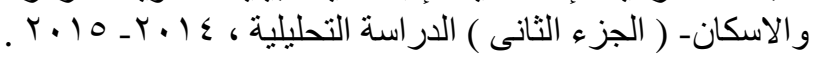

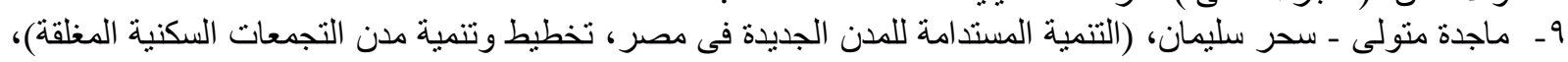

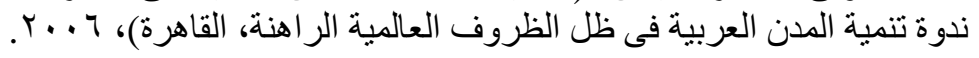

10- (www. google earth/historical imagery/2017).

11-http://www.marinapart.hu-2018.

12- http://www.cliffordelementarybilingual.com-2018

13- https://www.thepolisblog.org-2018

14- M.Metwally, S. Soliman, Impact of Gated Communities on urban Development of New Cities in Egypt, 6th. International conference of Research Network "Private urban Governance \&Gated Communities ",Istanbul ‘Sept. 8-11-2011

15- M.Metwally, S. Soliman, Major Trends of the Gated Communities Development in Egypt an Approach to Urban Sustainability "International conference-privat urban Governance \& Gated Communities ,University of Brighton , UK , 2013 